\title{
Optimal control of conventional hydropower plant retrofitted with a cascaded pumpback system powered by an on-site hydrokinetic system
}

\author{
Fhazhil Wamalwa ${ }^{\text {a,*, }}$, Sam Sichilalu a,b, Xiaohua Xia ${ }^{a}$ \\ ${ }^{a}$ Centre of New Energy Systems, Department of Electrical, Electronic and Computer Engineering, University of Pretoria, Pretoria \\ 0002, South Africa \\ ${ }^{b}$ Mosi-O-Tunya University of Science and Technology, Lusaka, Zambia
}

\begin{abstract}
This paper presents an optimal control strategy for a hydropower plant retrofitted with a hydrokineticpowered cascaded pumpback system in dry season. Pumpback operation aims at recycling a part of the down-stream discharge back to the main dam to maintain a high water level to optimise the energy value of the available water. The problem is formulated as a multi-objective optimisation problem to simultaneously minimise the grid pumping energy demand, minimise the wear and tear associated with the switching frequency of the pumps, maximise the restoration of the volume of the dam through pumpback operation and maximise the use of on-site generated hydrokinetic power for pumping operation. The performance of the proposed cascaded model is compared with the classical single pump pumped storage model. Simulation results based on a practical case study shows that the cascaded pumping model can reduce the pumping energy demand by upto $48.18 \%$ and increase the energy yield of the resultant system by upto $47.10 \%$ in dry season.
\end{abstract}

Keywords: Hydrokinetic generator; Cascaded-pumping; Pumpback operation; Hydropower; Hydraulic head; Optimal pumping strategy.

\footnotetext{
${ }^{*}$ Corresponding author. Tel. +27 61756 5168; Fax +27 123625000.

Email address: Fhazhil.Wamalwa@up.ac.za ; Fazil.wamalwa@gmail.com (Fhazhil Wamalwa)
} 


\begin{tabular}{|c|c|}
\hline Nomenclature & \\
\hline$n_{h, t}$ & a control variable denoting the number of hydrokinetic generators \\
\hline$u_{1}, u_{2}$ & state of switches for the pumps \\
\hline$P_{h, \text { nоm }}$ & the rate power output of a single hydrokinetic generator $(M W)$ \\
\hline$P_{h, t}$ & hydrokinetic generator power output $(M W)$ \\
\hline$P_{h g, t}$ & excess hydrokinetic power exported to the grid $(M W)$ \\
\hline$P_{h k, t}$ & hydrokinetic power supplied to meet the pumping power demand $(M W)$ \\
\hline$P_{K, t}$ & total pumping power demand of the pumpback system $(M W)$ \\
\hline$P_{K 1, t}$ & power demand by pump $\mathrm{K} 1(M W)$ \\
\hline$P_{K 2, t}$ & power demand by pump $\mathrm{K} 2(M W)$ \\
\hline$P_{g, t}$ & hydroelectric plant power output $(M W)$ \\
\hline$H_{o, t}$ & the hydraulic head of the dam $(m)$ \\
\hline$Q_{o, t}$ & turbine flow rate of the dam via the penstock $\left(\mathrm{m}^{3} / \mathrm{s}\right)$ \\
\hline$P_{g k, t}$ & Pumping power demand imported from the grid $(M W)$ \\
\hline$h_{u, t}$ & depth of the main dam $(m)$ \\
\hline$h_{r, t}$ & depth of the intermediate reservoir $(m)$ \\
\hline$\eta_{e}$ & the combined efficiency of the hydro turbine and the generator \\
\hline$P_{g}^{\min }, P_{g}^{\max }$ & minimum and maximum power output of a hydroelectric plant $(M W)$ \\
\hline$Q_{\text {in }}^{\circ}$ & upper reservoir in-stream flow rate $\left(\mathrm{m}^{3} / \mathrm{s}\right)$ \\
\hline$Q_{1}, Q_{2}$ & discharge rate of pumps $\mathrm{K} 1$ and $\mathrm{K} 2$ respectively $\left(\mathrm{m}^{3} / \mathrm{s}\right)$ \\
\hline$t_{s}$ and $k$ & sampling period (h) and $k_{t h}$ sampling interval \\
\hline$A_{u}$ & base area of the upper reservoir $\left(\mathrm{m}^{2}\right)$ \\
\hline$h_{u}^{\min }, h_{u}^{\min }$ & minimum and maximum water levels in the upper (dam) reservoir $(\mathrm{m})$ \\
\hline$A_{r}$ & base area of intermediate reservoir $\left(\mathrm{m}^{2}\right)$ \\
\hline$h_{r}^{\min }, h_{r}^{\min }$ & minimum and maximum water levels in the intermediate reservoir $(\mathrm{m})$ \\
\hline$H_{1}, H_{2}$ & net head of pump K1 and $\mathrm{K} 2$ respectively $(m)$ respectively \\
\hline$\eta_{k 1}, \eta_{k 2}$ & efficiency of pumps $\mathrm{K} 1$ and $\mathrm{K} 2$ respectively \\
\hline$P_{K}^{\min }, P_{K}^{\max }$ & minimum and maximum pumping power demand $(M W)$ \\
\hline$\eta_{t}, \eta_{g}$ & the hydrokinetic turbine and generator efficiency \\
\hline$C_{p}$ & coefficient of performance of the hydrokinetic turbine \\
\hline$A_{t}$ & cross sectional area of the hydrokinetic turbine $\left(\mathrm{m}^{2}\right)$ \\
\hline$v$ & river current velocity $(\mathrm{m} / \mathrm{s})$ \\
\hline$P_{h}^{\min }, P_{h}^{\max }$ & minimum and maximum hydrokinetic generator power output $(M W)$ \\
\hline & total number of sampling intervals \\
\hline$J$ & the objective function \\
\hline$P_{l d, t}$ & total grid load demand $(M W)$ \\
\hline $\operatorname{Res}_{\text {opt }}$ & The optimal change in the intermediate reservoir water level due to pumping operation $(\mathrm{m})$ \\
\hline$H_{K 1}$ & Change in the intermediate reservoir water level due to K1 operation $(m)$ \\
\hline$H_{K 2}$ & Change in the intermediate reservoir water level due to $\mathrm{K} 2$ operation $(\mathrm{m})$ \\
\hline$H_{Q o}$ & Change in the main dam water level due to $Q_{o}(m)$ \\
\hline$H_{\text {inflow }}$ & Change in the main dam water level due to the combined state inflows $(m)$ \\
\hline$H_{o p t}$ & Optimal change in the main dam water level due to the combined state inflows and outflows $(\mathrm{m})$ \\
\hline$E_{g}$ & Total energy produced by the hydro-turbine generator over the 24-h control period $(M W h)$ \\
\hline$E_{h}$ & Total energy produced by the hydrokinetic system over the 24 -h control period $(M W h)$ \\
\hline$E_{h k}$ & Total hydro-turbine energy consumed by pumping system over the 24 -h control period $(M W h)$ \\
\hline$E_{h g}$ & Total hydrokinetic energy exported to the grid over the $24-\mathrm{h}$ control period $(M W h)$ \\
\hline$E_{g k}$ & Total grid energy supplied to the pumping system over the 24 -h control period $(M W h)$ \\
\hline$E_{\text {opt }}$ & Total optimal energy output of the system over the $24-\mathrm{h}$ control period $(M W h)$ \\
\hline
\end{tabular}




\section{Introduction}

Coping with the intermittent nature of hydropower generation is one of the main challenges faced by hydropower system operators. In the rainy season, the system operators are faced with a deluge of floods leading to excess power generation and spillage. The situation reverses in dry seasons with low in-stream flows where plant operators are compelled to curtail generation due to low water levels in the dams. The effects of this fluctuating nature of hydropower is more pronounced in predominantly hydropower systems in drought prone regions such as Southern Africa. Prolonged droughts experienced in the region in recent years have resulted in acute power shortages in many countries with Tanzania, Zimbabwe and Zambia worst affected because of their high reliance on hydropower ${ }^{1}$. The projected decrease in rainfall in Southern Africa underscores that the problem is bound to become more pronounced $[1,2,3]$. This problem underscores the need to re-model the existing hydropower plants in the region to maximise the economic value of the available water. To this end, substantive researches on optimal control of hydropower systems have been accomplished in the current literature [4,5]. The main research focus is optimal planning and water water resource allocation [6,7], optimal storage and scheduling of hydroelectric power generators $[8,9,10,11]$. Optimal control of pumped storage (PS) systems in deregulated energy markets has also been studied exptensively $[12,13,14,15]$. In this case, the cheap-to-buy off-peak energy is used for pumping operation and later recovered and sold at peak prices to generate profits [13].

In systems with big disparities between peak and off-peak power demand, pumpback operation during offpeak hours to maintain a high reservoir water level for peak generation has been studied in [16, 17]. In [16], a pumpback retrofit is proposed to optimise energy yield of the plant over a 12-month control period with seasonal changes in in-stream flows as a source of uncertainty. However, the author does not consider minimisation of pumping energy resulting in high pumping energy demand over the control period. In [17], a pumpback retrofit is proposed for a high head application to maximise the energy output and revenue of a hydropower plant in a market with deterministic but time-varying energy prices over a 24-h control horizon with a constant in-stream flow. However, the high head losses associated with a single high lift pump has the potential to degrade the economic viability of the model. For instance, the model in [17] is proposed for application to the $150 \mathrm{~m}$ head Eugenia Fall hydropower plant in Ontario. Pumping losses associated with such a high head high flow pumping could derail the economic viability of the model.

In this paper, unlike in the cited works, we seek to simultaneously minimise the pumping energy demand and the wear and tear associated with switching frequency of the pumping system. We further propose an on-site hydrokinetic energy conversion (HEC) system for powering the pumpback system instead of full reliance on grid power. To minimise pumping power demand for high head applications, we further propose a cascaded pumpback model with two pumps to reduce the hydraulic head to be bridged by a single high power high lift pump. A cascaded model reduces the overall pumping problem into a multi-pump operation problem which can be solved to minimise the pumping power demand of the resultant system. Defining a pump switch as a state transition of a pump from off to on state [18], the problem of optimal switching control of a pumping system to minimise the pumping energy demand has been solved in $[19,20]$. Since pumping energy demand over a given control period is proportional to the number of switches or the cumulative operating hours, a pumping optimisation problem can be formulated to minimise the number of pump switches [21] as well as the cumulative number of operating hours [18]. The main contribution of this work include: (1) The use of alternative hydrokinetic (HK) energy for pumping operation, (2) cascading pumpback operation to minimise pumping power and energy demand for high head applications and (3) minimisation of the wear and tear costs of the pumps by minimising the number of switches of each of the pumps. This paper is organised as follows: Sections 2 and 3 present the mathematical formulation and discrete time modelling of the system respectively. Section 4 presents the simulation results and discussion while the last part, section 6,concludes the paper.

\footnotetext{
${ }^{1} \mathrm{mg} . c 0 . z a /$ article/2016-01-14-droughts-devastating-ripple-effect
} 


\section{Mathematical model formulation}

\subsection{Schematic model layout}

Figure 1 shows the schematic layout of the proposed hydropower model with cascaded pumpback retrofit. In the figure, $H_{o, t}(m)$ is the system head while $h_{u, t}(m)$ is the height (depth) of the dam. The system comprises the conventional hydropower system, the HEC system and the cascaded pumpback retrofit. The conventional hydropower system comprises the main dam and the hydro-turbine generator in the power house. The HEC system comprises $n_{h}$ HK generators installed in the tail-race of the power plant to harness a part of the kinetic energy of free-flowing water to power the pumpback system. The pumpback system comprises pumps $K 1$ and $K 2$ powered through their respective switches $u_{1}$ and $u_{2}$ and the intermediate reservoir $R$.

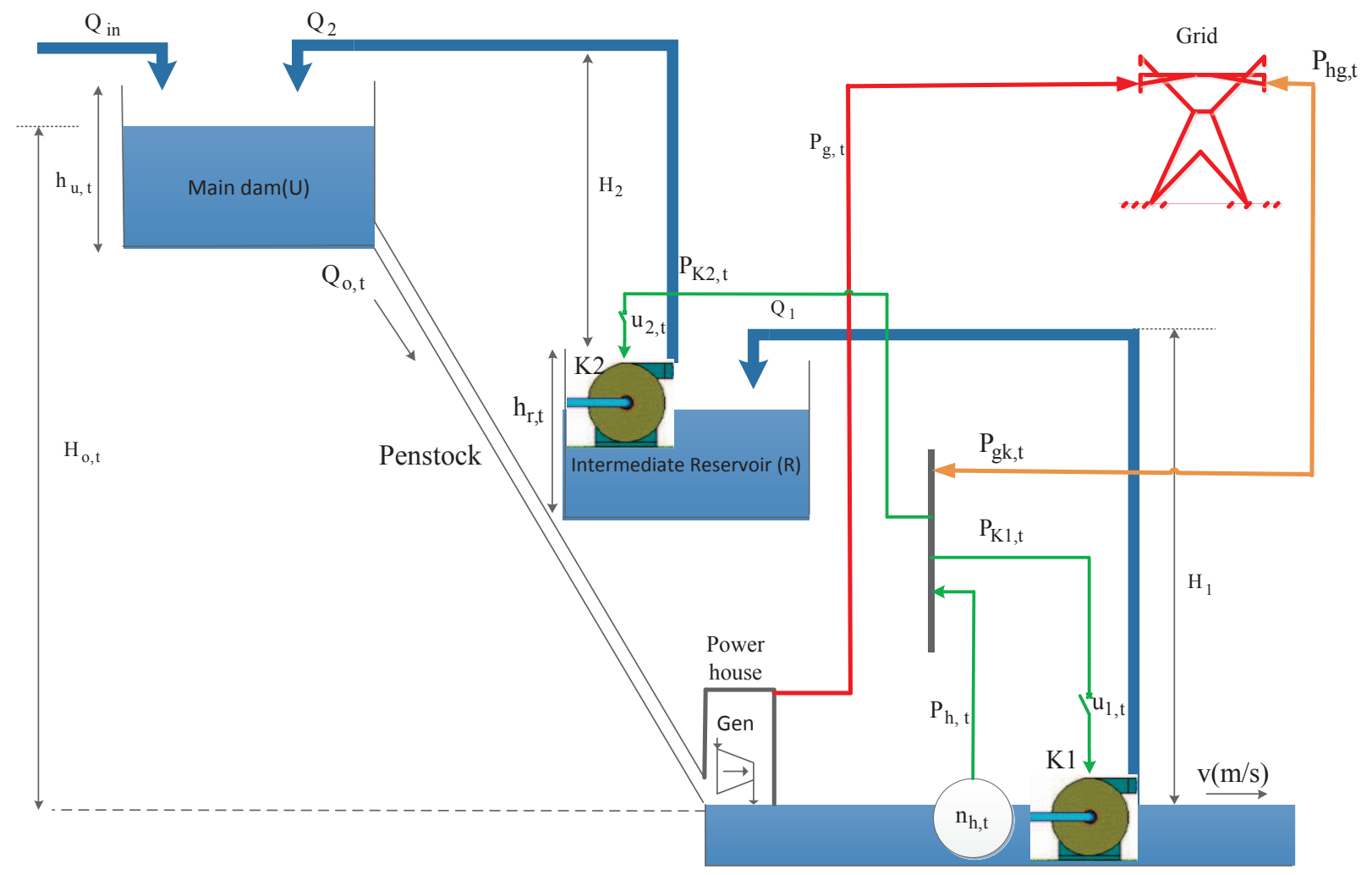

Figure 1: Schematic layout of the hydropower system with cascaded HK-powered pumpback system

In the proposed model, the on-site generated HK power will be supplied to meet the pumping power demand and the surplus exported to the grid in cases when the generated HK power is more than the pumping power demand. Conversely, when the HK power output is less than the pumping power demand, the deficit will be offset by the grid power import, $P_{g k, t}$. In Figure $1, P_{g, t}$ and $P_{h, t}$ are respectively, the hydro-turbine generator power output and the HK power output. The fraction of HK power supplied to meet the pump load is denoted by $P_{h k, t}$ while $P_{h g, t}$ is the excess on-site generated HK power exported to the grid. The notations $P_{K 1, t}$ and $P_{K 2, t}$ are respectively, the pump power demand for pumps $K 1$ and $K 2$. The quantities $Q_{i n}, Q_{1}, Q_{2}$ and $Q_{o, t}$ are respectively, the constant in-stream flow rate, the flow rates of pumps $K 1$ and $K 2$ and turbine turbine flow rate expressed in $\mathrm{m}^{3} / \mathrm{s}$. The speed of water downstream, $v \mathrm{~m} / \mathrm{s}$, is assumed to be constant over the 24 hour control period in this paper. It is also assumed that down-stream river flow is un-regulated and the dam is a single purpose dam for hydropower generation only. In this model, the control variables include $Q_{o, t}, n_{h, t}, P_{g k, t}, P_{h k, t}, P_{h g, t}$ and the state of the pump switches $u_{1, t}$ and $u_{2, t}$. The water level in the main dam $h_{u, t}$ and the level in the intermediate reservoir $h_{r, t}$ form the state variables of the system. 


\subsection{Sub models}

\subsubsection{Conventional hydropower model}

Given the density of water, $\rho=1000 \mathrm{~kg} / \mathrm{m}^{3}$ and gravitational acceleration $g=9.81 \mathrm{~m} / \mathrm{s}^{2}$, the theoretical power output of a hydro-turbine generator $P_{g, t}(\mathrm{MW})$ can be expressed as a non-linear function of the net head of the system $H_{o, t}(\mathrm{~m})$ and the turbine flow rate $Q_{o, t}\left(\mathrm{~m}^{3} / \mathrm{s}\right)$ as follows [22]:

$$
P_{g, t}=9.81 \eta_{e} H_{o, t} Q_{o, t} \times 10^{-3}, \quad 0 \leq Q_{o, t} \leq A_{p} \sqrt{2 g H_{o}^{\max }}
$$

where $\eta_{e}, \mathrm{~A}_{\mathrm{p}}\left(\mathrm{m}^{2}\right)$ and $\mathrm{H}_{\mathrm{o}}^{\max }(\mathrm{m})$ are respectively, the overall efficiency of the hydro-turbine generator, the cross-sectional area of the penstock and the maximum head of the system.

If a cylindrical model with a base area $\mathrm{A}_{\mathrm{u}}\left(\mathrm{m}^{2}\right)$ is assumed for the main dam and the precipitation to and evaporation losses from the water surface is neglected for a short scheduling time, the water mass balance of the dam can be expressed by a first order differential equation as follows [16]:

$$
h_{u, t+1}=h_{u, t}+\frac{t_{s}}{A_{u}}\left[Q_{i n}+u_{2, t} Q_{2}-Q_{o, t}\right],
$$

where $h_{u, t}$ and $h_{u, t+1}$ are respectively, the dam water level at the end of time $t$ and the next time period $t+1$. The notation $u_{2, t}$ is a binary variable $[0,1]$ denoting the on/off state of the switch of pump $K 2$ while $t_{s}$ is the sampling time. For optimal operation, the water level in the dam must not exceed its dimensions and must not fall below the minimum operational limit. Therefore, the dam level is restricted to lie within $h_{u, t} \in\left[h_{u}^{\min }, h_{u}^{\max }\right]$ where $h_{u}^{\min }$ and $h_{u}^{\max }$ are respectively, the minimum and maximum operational bounds of the dam. Similarly, if we assume a cylindrical model with a base area $A_{r}\left(\mathrm{~m}^{2}\right)$ and zero evaporation and precipitation effects for a short scheduling period, the water mass balance of the intermediate reservoir can be expressed in terms of reservoir height as follows:

$$
h_{r, t+1}=h_{r, t}+\frac{t_{s}}{A_{u}}\left[u_{1, t} Q_{1}-u_{2, t} Q_{2}\right],
$$

where $h_{r, t}(\mathrm{~m})$ and $h_{r, t+1}(\mathrm{~m})$ are respectively, the height of water in the reservoir at the end of time $t$ and at the end of the next time phase $t+1$. Similarly, the water level in the intermediate reservoir at any given time is constrained to lie within $h_{r, t} \in\left[h_{r}^{\min }, h_{r}^{\max }\right]$ where $h_{r}^{\min }$ and $h_{r}^{\max }$ are respectively, the minimum and the maximum operational bounds of the intermediate reservoir.

\subsection{Cascaded pumping model}

The pumpback operation conserves water by recycling a part of the down-stream discharge back to the main dam to maintain a high level for optimal hydropower generation; the amount of water discharged for each unit of hydropower generated increases with a decrease in the level of water in the dam. The proposed model employs constant speed pumps controlled by on/off switches. Therefore, power demanded by each of the pumps can be expressed as follows [23]:

$$
P_{K i, t}=\frac{9.81 H_{i} Q_{i} u_{i, t}}{\eta_{k i}} \times 10^{-3}, \quad i=1,2,
$$

where $P_{K i, t}(\mathrm{MW}), H_{i}$ and $Q_{i}$ are respectively, the power demanded by pump $K i$ at time $t$, the hydraulic head of pump and the flow rate of pump $K i$. The coefficient $\eta_{k i}$ denotes the combined efficiency of pump $K i$ and its drive motor. In the proposed model, the pumping power demand is met by the combined power flows from the HEC, $P_{h k, t}$ and the grid import, $P_{g k, t}$. Therefore, the power balance of the pumpback system can be expressed as follows:

$$
P_{h k, t}+P_{g k, t}=P_{K 1, t} u_{1, t}+P_{K 2, t} u_{2, t}
$$

where $P_{h k, t}$ is the fraction of the on-site generated HK power supplied to meet the pumping power demand at any given time $t$. 


\subsubsection{HEC system}

Unlike the conventional hydro turbine generator that requires a water head, a HK generator is designed to extract the kinetic energy of the run-off water at low to zero hydraulic head and convert it into electrical energy [24]. The operation principle of a HK turbine is similar to that of a wind turbine and thus, the power output of a HEC system can be expressed by equation (6) adopted from[25].

$$
P_{h, t}=\frac{1}{2} C_{p} \eta_{t} \eta_{g} A_{t} \rho v^{3} \times 10^{-6},
$$

where $C_{p}, \mathrm{~A}_{\mathrm{t}}\left(\mathrm{m}^{2}\right)$ and $v(\mathrm{~m} / \mathrm{s})$ are respectively, the coefficient of performance of the HEC system limited by Betz law [26], the area swept by the HK turbine rotor and the after-bay speed of water. The coefficients $\eta_{t}$ and $\eta_{g}$ are respectively, the efficiencies of the HK turbine and the generator while $\rho$ is the density of water expressed in $\mathrm{kg} / \mathrm{m}^{3}$. In general, the power output of the HEC system $P_{h, t}(\mathrm{MW})$ depends on the number of the HK generators in parallel operation $n_{h, t}$ and the nominal power rating of each of the HK generators $P_{h, \text { nom }}$ expressed by equation (7).

$$
P_{h, t}=P_{h, \text { nom }} n_{h, t} .
$$

Therefore, the power balance of the HEC system is expressed as follows:

$$
P_{h, t}=P_{h k, t}+P_{h g, t},
$$

where $P_{h k, t}$ and $P_{h g, t}$ are respectively, the HK power supplied to meet the pumping power demand and the excess HK power injected into the grid.

\section{Discrete model of the system}

The state dynamics of the dam equation (2) can be re-expressed in discrete time domain by a first order differential equation as follows:

$$
h_{u, k+1}=h_{u, k}+\frac{t_{s}}{A_{u}}\left[Q_{i n}+u_{2, k} Q_{2}-Q_{o, k}\right],
$$

which can be expressed iteratively as follows:

$$
\begin{aligned}
k=0 ; & h_{u, 1}=h_{u, 0}+\frac{Q_{i n} t_{s}}{A_{u}}+\frac{u_{2,0} Q_{2} t_{s}}{A_{u}}-\frac{Q_{o, 0} t_{s}}{A_{u}}, \\
k=1 ; & h_{u, 2}=h_{u, 1}+\frac{Q_{i n} t_{s}}{A_{u}}+\frac{u_{2,1} Q_{2} t_{s}}{A_{u}}-\frac{Q_{o, 1} t_{s}}{A_{u}}, \\
k=2 ; & h_{u, 3}=h_{u, 2}+\frac{Q_{i n} t_{s}}{A_{u}}+\frac{u_{2,2} Q_{2} t_{s}}{A_{u}}-\frac{Q_{o, 2} t_{s}}{A_{u}}, \\
& \vdots \\
& h_{u, k}=h_{u, 0}+\frac{t_{s} Q_{i n}}{A_{u}}+\frac{t_{s} Q_{2}}{A_{u}} \sum_{j=1}^{k} u_{2, j}-\frac{t_{s}}{A_{u}} \sum_{j=1}^{k} Q_{o, j}, \quad(1 \leq j \leq k),
\end{aligned}
$$

where $k$ is the sampling interval and $h_{u, 0}$ is the initial water level in the dam at time $k=0$. Therefore, the water level constraint of the main dam can be expressed in discrete time domain as follows:

$$
h_{u}^{\text {min }} \leq h_{u, 0}+\frac{t_{s} Q_{i n}}{A_{u}}+\frac{t_{s} Q_{2}}{A_{u}} \sum_{j=1}^{k} u_{j}-\frac{t_{s}}{A_{u}} \sum_{j=1}^{k} Q_{o, j} \leq h_{u}^{\max } .
$$

Similarly, the intermediate reservoir water mass balance equation (3) can be re-expressed in discretised form as follows: 


$$
\begin{array}{ll} 
& h_{r, k+1}=h_{r, k}+\frac{t_{s}}{A_{r}}\left[u_{1, k} Q_{1}-u_{2, k} Q_{2}\right], \\
k=0 ; & h_{r, 1}=h_{r, 0}+\frac{t_{s}}{A_{r}}\left[u_{1,0} Q_{1}-u_{2,0} Q_{2}\right], \\
k=1 ; & h_{r, 2}=h_{r, 1}+\frac{t_{s}}{A_{r}}\left[u_{1,1} Q_{1}-u_{2,1} Q_{2}\right], \\
k=2 ; & h_{r, 3}=h_{r, 2}+\frac{t_{s}}{A_{r}}\left[u_{1,2} Q_{1}-u_{2,2} Q_{2}\right], \\
\vdots & h_{r, k}=h_{r, 0}+\frac{t_{s} Q_{1}}{A_{r}} \sum_{j=1}^{k} u_{1, j}-\frac{t_{s} Q_{2}}{A_{r}} \sum_{j=1}^{k} u_{2, j}, \quad(1 \leq j \leq k),
\end{array}
$$

where $h_{r, 0}$ is the water level in the intermediate reservoir when $k=0$. The bounds of water level in the intermediate reservoir is expressed in discretised form as follows:

$$
h_{r}^{\min } \leq h_{r, 0}+\frac{t_{s} Q_{1}}{A_{r}} \sum_{j=1}^{k} u_{1, j}-\frac{t_{s} Q_{2}}{A_{r}} \sum_{j=1}^{k} u_{2, j} \leq h_{r}^{\max } .
$$

\subsection{Objective function}

The problem is formulated as a multi-objective optimisation problem given by equation (14). The first performance index $t_{s} \sum_{k=1}^{N} P_{g k, k}$, minimises the grid pumping energy demand. The second part $\sum_{k=1}^{N}\left(s_{1, k}+s_{2, k}\right)$, minimises the switching frequency of the two pumps, $\mathrm{K} 1$ and $\mathrm{K} 2$, to reduce on tear-and-wear. The third objective $t_{s} \sum_{k=1}^{N} Q_{2} u_{2, k}$, maximises the restoration of the water volume in the main dam through pumpback operation while the fourth objective, $t_{s} \sum_{k=1}^{N} P_{h k, k}$ maximises the use of hydrokinetic energy to power the pumping system. Finally, the overall performance index is written as follows:

$$
J=t_{s}\left(w_{1} \sum_{k=1}^{N} P_{g k, k}+w_{2} \sum_{k=1}^{N}\left(s_{1, k}+s_{2, k}\right)-w_{3} \sum_{k=1}^{N} Q_{2} u_{2, k}-w_{4} \sum_{k=1}^{N} P_{h k, k}\right) .
$$

The control horizon is 24 hours with a sampling time $t_{s}=0.25 h . k=1, \ldots, N$ is sampling interval and $N$ is the total number of intervals.

In general, the maintenance costs of a pump relates to wear and tear costs associated with the number of switching times [27]. Therefore, minimisation of the switching times of a pump reduces its associated wear and tear costs. In this paper, the Pretorian method used in [27] is used to minimise the switching frequency of the pumps. This method introduces an auxiliary variable $s_{k}$ represented by a value of 1 whenever a transition from off to on state of the pump occurs. Minimising the state transitions of the auxiliary variable $s_{k}$ reduces the switching frequency of the pump by augmenting the adjacent on/off switches and consequently reducing the overall number of switches of each of the pumps over the $24 \mathrm{~h}$ control horizon. 
The objective function equation (14) is solved subject to the following constraints:

$$
\begin{aligned}
& h_{u}^{\text {min }} \leq h_{u, 0}+\frac{t_{s} Q_{i n}}{A_{u}}+\frac{t_{s} Q_{2}}{A_{u}} \sum_{j=1}^{k} u_{2, j}-\frac{t_{s}}{A_{u}} \sum_{j=1}^{k} Q_{o, j} \leq h_{u}^{\text {max }}, \\
& h_{r}^{\text {min }} \leq h_{r, 0}+\frac{t_{s} Q_{1}}{A_{r}} \sum_{j=1}^{k} u_{1, j}-\frac{t_{s} Q_{2}}{A_{r}} \sum_{j=1}^{k} u_{2, j} \leq h_{r}^{\text {max }}, \\
& P_{g, k}+P_{h g, k}=P_{l d, k}, \\
& P_{h, k}=P_{h k, k}+P_{h g, k} \\
& P_{h k, k}+P_{g k, k}=u_{1, k} P_{K 1}+u_{2, k} P_{K 2}, \\
& P_{g}^{\min } \leq P_{g, k} \leq P_{g}^{\max }, \quad 0 \leq Q_{o, k} \leq A_{p} \sqrt{2 g H_{o}^{\max }} \\
& P_{h}^{\min } \leq P_{h, k} \leq P_{h}^{\max } \\
& P_{h g}^{\min } \leq P_{h g, k} \leq P_{h g}^{\max } \\
& P_{h k}^{\min } \leq P_{h k, k} \leq P_{h k}^{\max } \\
& P_{g k}^{\min } \leq P_{g k, k} \leq P_{g k}^{\max } \\
& u_{i, k}-s_{i, k} \leq 0, i=1,2 \quad s_{i, k} \in[0,1] \\
& u_{i, k}-u_{i, k-1}-s_{i, k} \leq 0, i=1,2 \\
& u_{i, k} \in[0,1], i=1,2, \quad(1 \leq k \leq N),
\end{aligned}
$$

where $\sum_{j=1}^{4} w_{j}=1$ is the weighting factors that determine the relative importance of each of the objective vectors. Inequalities (15) and (16) are respectively, the state constraints of the dam and the intermediate reservoir bounded by their respective minimum and maximum allowable limits. The equalities (17) and (18) are the grid power balance and the HK power balance respectively. Equality (17) shows that the power supplied to the grid is the sum of the hydro turbine generator output and the excess HK power. Equality (19) shows that the total power demand by the pumpback system is the sum of the HK power supplied to the pumps and the supplementary grid power import. Inequalities (20), (21), (22), (23) and (24) are respectively, the control variable bounds for: the hydro-turbine generator power output which depends on the turbine flow rate bounds, the HEC system's power output, the surplus HK power exported to the grid, the HK power supplied to meet the pumping power demand and the supplementary grid power imported to offset pumping power deficit. The inequality 25 initialises the auxiliary variable $s_{i, k}$ as the initial status of $u_{i, k}$ while the inequality 26 favours the control with less switching frequency. This auxiliary constraints allows the objective function 14 to simultaneously minimise the system pumping energy demand, minimise the maintenance costs by minimising the number of on/off switching of the pumping system and maximise the pumping restoration of the volume of the main dam. Equation (27) is a binary control variable constraint for the switches $u_{1}$ and $u_{2}$ that control pumps $K 1$ and $K 2$ respectively.

\subsection{Algorithm formulation and implementation in MATLAB}

The proposed model yields a constrained mixed integer non-linear problem solvable by the OPTI toolbox SCIP algorithm in MATLAB. The control variables are as follows: a binary variables $u_{1, k}$ and $u_{2, k}$, real number variables; $Q_{o, k}, P_{h k, k}, P_{h g, k}$ and $P_{g k, k}$, an integer variable $n_{h, k}$ and the auxiliary variable $s_{i, k}, i=1,2$. The objective function equation (14) is expressed in its canonical form by equation (29). 
subject to

$$
\left\{\begin{array}{l}
\mathbf{A X} \leq \mathbf{b} \\
\mathbf{A}_{\mathbf{e q}} \mathbf{X}=\mathbf{b}_{\mathbf{e q}} \\
\mathbf{L}_{\mathbf{B}} \leq \mathbf{X} \leq \mathbf{L}_{\mathbf{B}} .
\end{array}\right.
$$

where $\mathbf{A X} \leq \mathbf{b}$ is the inequality constraints, $\mathbf{A}_{\mathbf{e q}} \mathbf{X}=\mathbf{b}_{\mathbf{e q}}$ is the equality constraints and $\mathbf{L}_{\mathbf{B}} \leq \mathbf{X} \leq \mathbf{L}_{\mathbf{B}}$ is the lower and the upper bounds of the control variables.

The vector $\mathbf{X}$ contains all the control variables of the model expressed by equation (31).

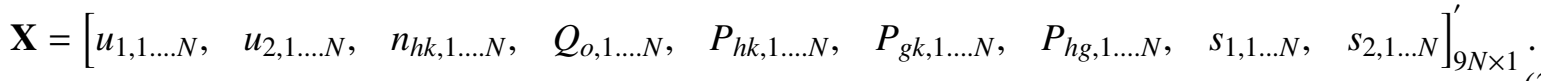

From the objective function equation (14):

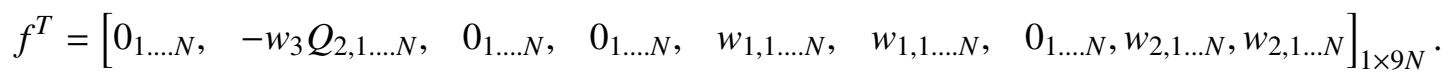

The lower and the upper bounds of the control variables are expressed by equation (33) and equation (34). Lower bounds

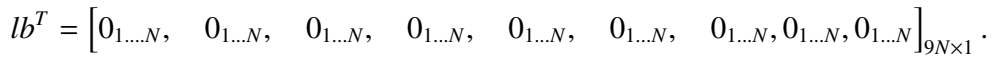

Upper bounds

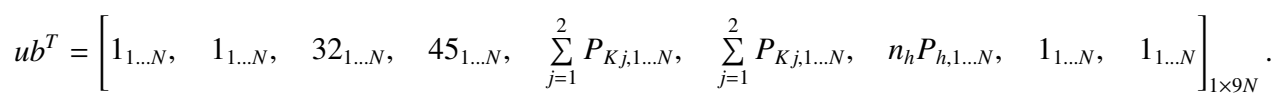

The detailed formulation of the inequality and equality constraints of the problem are attached to Appendix A.

\subsection{Case study}

The case study is based on Pangani fall hydropower plant (HPP), one of the three HPPs that form a cascade of the Pangani Hydropower system located on Pangani River in Tanzania. The first one is Nyumba ya mungu $(\mathrm{NyM})$ plant, a $2 \times 4 M W$ hydropower plant located at NyM dam which discharges into the $2 \times 10.5 M W$ Hale HPP. From the Hale power plant, water flows into the Pangani fall dam that feeds the $2 \times 34 M W$ Pangani fall HPP which drains into the Indian Ocean $64 \mathrm{~km}$ downstream. The Pangani hydropower system has a total installed capacity of $91.5 \mathrm{MW}$. However, the capacity drops to $30 \%$ during dry seasons, a situation which has worsened in recent years due to prolonged droughts ${ }^{2}$. Hydropower production of the Pangani fall (HPP) has declined in the last 10 years [28] due to low river discharge and reached the lowest point in 2014 with a production of $25 \mathrm{MW}$ that threatened its shutdown ${ }^{3}$. To validate the economic advantages of the proposed cascaded pumpback model over the classical single pump model, the performance of the HPP is simulated over a control period of 24 hours. The simulation assumes a normal average day in the dry and the rainy seasons with a constant river in-stream discharge, $q_{i n}$. However, the authors are aware that in practice, the river discharge may vary if the system is modelled for a longer horizon such as for a month or a year depending on precipitation patterns of the region.

\subsubsection{Pangani fall hydropower plant}

Pangani fall HPP is fed by Pangani fall dam with a live capacity of $0.8 \times 10^{6} \mathrm{~m}^{3}$. The reservoir has a maximum and minimum hydropower operating level by volume of $1.7 \times 10^{6} \mathrm{~m}^{3}$ and $0.9 \times 10^{6} \mathrm{~m}^{3}$ respectively. The plant is installed with $2 \times 34$ MW SAV340/110/14 generators with a nominal capacity of $2 \times 40 \mathrm{MVA}$ and a power factor of 0.85 . The plant turbines' speed is 428 revolutions per minute (rpm) [29]. Table 1

\footnotetext{
${ }^{2}$ http://www.iucn.org/dbtw-wpd/edocs/2007-002.pdf

${ }^{3}$ http://www.theeastafrican.co.ke/news/Tanzania-to-switch-off-all-hydropower-stations/-/2558/2905900/-/ep5kq9/-/index.html
} 
shows the salient features of Pangani fall HPP [29]. In this case study, an initial volume of $1.1 \times 10^{6} \mathrm{~m}^{3}$ is assumed, which is a typical average capacity of Pangani fall dam in the dry season.

Table 1: Salient features of Pangani fall hydropower plant

\begin{tabular}{lcccccccc}
\hline Res-vol $\left(\mathrm{m}^{3}\right)$ & $\mathrm{h}_{\mathrm{u}}^{\max }(\mathrm{m})$ & $\mathrm{h}_{\mathrm{u}}^{\min }(\mathrm{m})$ & $\mathrm{H}_{o}(m)$ & $P_{g}($ rated $)(\mathrm{MW})$ & $Q_{o}^{\max }\left(\mathrm{m}^{3} / \mathrm{s}\right)$ & $\mathrm{Q}_{\mathrm{o}}^{\min }\left(\mathrm{m}^{3} / \mathrm{s}\right)$ & $\mathrm{Q}_{\text {in }}\left(\mathrm{m}^{3} / \mathrm{s}\right)$ & $\eta_{e}$ \\
\hline $1.4 \times 10^{6}$ & 177.5 & 176 & 170 & 68 & 45 & 9.0 & 12.5 & 0.93 \\
\hline
\end{tabular}

\subsubsection{Intermediate reservoir parameters}

The intermediate reservoir, $R$, proposed in this model is used to create an intermediate pumping stage for operation of pumps $K 1$ and $K 2$ in cascade as shown in Figure 1. This reservoir is sized by rule of thumb to ensure 12-h continuous outward pumping by $\mathrm{K} 2$ without restorative inward pumping by $\mathrm{K} 1$ and 12-h inward pumping by K1 without outward pumping by K2. Since the two pumps $K 1$ and $K 2$ are sized equally, the maximum capacity of the intermediate reservoir can be approximated to $2.4 \times 10^{5} \mathrm{~m}^{3}$ with a design radius of $35.60 \mathrm{~m}$ and a design height of $60.0 \mathrm{~m}$. Table 2 shows the design specifications of the intermediate reservoir.

Table 2: Design specifications of the intermediate reservoir

\begin{tabular}{lccccc}
\hline Design shape & Design capacity $\mathrm{m}^{3}$ & Radius $(m)$ & Design height $(m)$ & $\mathrm{h}_{\mathrm{r}}^{\max }(\mathrm{m})$ & $\mathrm{h}_{\mathrm{r}}^{\min }(\mathrm{m})$ \\
\hline Cylindrical & $2.40 \times 10^{5}$ & 35.60 .00 & 60.00 & 60.00 & 10.00 \\
\hline
\end{tabular}

\subsubsection{Cascaded pumping system parameters}

The pumps used in the case study are the SJT vertical turbine pumps from Sulzar Ltd with a performance range of upto $17.3 \mathrm{~m}^{3} / \mathrm{s}$ flow rate, maximum head of $110 \mathrm{~m}$ and pressure of upto $64 \mathrm{bar}^{4}$. Table 3 shows the specifications of the pumps used in the case study.

Table 3: Design Specifications of the pumping system

\begin{tabular}{lcccccc}
\hline$Q_{1}\left(\mathrm{~m}^{3} / \mathrm{s}\right)$ & $Q_{2}\left(\mathrm{~m}^{3} / \mathrm{s}\right)$ & $\mathrm{H}_{1}(\mathrm{~m})$ & $\mathrm{H}_{2}(\mathrm{~m})$ & Head range $(\mathrm{m})$ & Pressure (bar) & $\eta_{p}$ \\
\hline 5.5 & 5.5 & 85 & 85 & upto 110 & up to 64 & 0.90 \\
\hline
\end{tabular}

\subsubsection{Hydrokinetic generator parameters}

The hydrokinetic energy conversion system used in the case study comprise of the CC035A river-instream turbine models developed by the Clean Current Renewable Energy Systems Inc ${ }^{5}$ and the flooded, permanent magnet generators. The CC035A turbine has a rotor diameter of $3.5 \mathrm{~m}$ and requires a minimum river depth of $7.0 \mathrm{~m}$ for effective deployment. The technical specifications of the HK turbines used in this paper are given in Table 4. $\eta_{t}$ denotes the efficiency of the mechanical gear box of the turbine. However, the Betz limit, $C_{p}$ is factored in the power output model given in equation (6).

Table 4: Hydrokinetic turbine specifications

\begin{tabular}{lcccccccc}
\hline Model & $n_{h}$ & $P_{h}(\mathrm{~kW})$ & $A_{t}\left(\mathrm{~m}^{2}\right)$ & $V_{\text {rated }}(\mathrm{m} / \mathrm{s})$ & $\eta_{t}(\%)$ & $\eta_{g}(\%)$ & $\rho_{w}\left(\mathrm{~kg} / \mathrm{m}^{3}\right)$ & $C_{p}$ \\
\hline CC035A & 26 & 65 & 9.6 & 3.0 & 0.9 & 0.85 & 1000 & 0.45 \\
\hline
\end{tabular}

The CC035A HK turbine model has a rated power output of $65 \mathrm{~kW}$ and a nominal revolution per minute $(\mathrm{rpm})$ of 75 . It operates optimally in a current speed range of $1.5-3.7 \mathrm{~m} / \mathrm{s}$. The hydrokinetic generator has a nominal output of $65 \mathrm{~kW}$.

\footnotetext{
${ }^{4}$ https://www.sulzer.com/en/Products-and-Services/Pumps-and-Systems/Vertical-Pumps/Vertical-Wet-Pit-Pumps/SJT-VerticalTurbine-Pumps

${ }^{5} \mathrm{http} / / /$ www.cleancurrent.com/river-turbines
} 


\subsubsection{Uncertainty analysis of the demand load}

There are several techniques used in sensitivity (uncertainty) analysis in a given model to determine its viability and reliability at a design stage. In this paper we adopted the methodology used in [30] to ascertain the confidence level of the load demand in the case study. The random error (noise) in addition to the instrument's absolute uncertainty is introduced in the load demand which in this case is the recorded load profile of the hydropower plant referred to as the measured value. The true (accepted) values are then estimated from the measured (corrupted) values. The resulting difference between accepted and corrupted values is due to random errors. For analysis purposes, random errors are generated in MATLAB software with a distribution mean of 0 and standard deviation equal to 1 which is then multiplied by the absolute uncertainty of the wattmeter $\sigma_{\text {m,meas }}= \pm 0.01$; a value which is often given by the manufacturer of the demand measuring instrument.

$$
Z_{m}=A_{m}+R A N D_{m} * \sigma_{m, \text { meas }}
$$

where $Z_{m}, A_{m}, R A N D_{m}$ and $\sigma_{m, \text { meas }}$ are respectively, the measured or experimental value of $m$ th measurement, the true value, the random noise and the standard deviation of the $m$ th measurement while $m=1, \ldots, 24$ is the number of measurements. The Pangani hydropower load demand profile is analysed for sensitivity and the results are shown in Table 5. Further analysis is done to determine the relative uncertainty of each given measurement.

$$
\text { Relative uncertainty }(\%)=\frac{\text { Absolute uncertainty }}{\text { Measured value }} \text {. }
$$

In this case, the weakest link rule ${ }^{6}$ is applied where the measurement with the largest relative uncertainty is picked from Table 5. In this case, the largest relative uncertainty is $0.022 \%$ which is used to determine the final objective function's absolute uncertainty.

Table 5: Uncertainty analysis of the Pangani fall HPP on load demand profile

\begin{tabular}{cccccc}
\hline Measured Values ( MW) & Rand error & $\sigma_{\text {m,meas }}$ & True Values $(\mathrm{MW})$ & absolute Uncertainty & Relative Uncertainty \\
\hline 50 & 0.534 & 0.01 & 49.995 & $(50 \pm 0.01)$ & $0.020 \%$ \\
50 & 0.885 & 0.01 & 49.991 & $(50 \pm 0.01)$ & $0.020 \%$ \\
50 & 0.899 & 0.01 & 49.991 & $(50 \pm 0.01)$ & $0.020 \%$ \\
50 & 0.626 & 0.01 & 49.994 & $(50 \pm 0.01)$ & $0.020 \%$ \\
60 & 0.138 & 0.01 & 59.999 & $(60 \pm 0.01)$ & $0.017 \%$ \\
60 & 0.218 & 0.01 & 59.998 & $(60 \pm 0.01)$ & $0.017 \%$ \\
60 & 0.182 & 0.01 & 59.998 & $(60 \pm 0.01)$ & $0.017 \%$ \\
60 & 0.042 & 0.01 & 60.000 & $(60 \pm 0.01)$ & $0.017 \%$ \\
60 & 0.107 & 0.01 & 59.999 & $(60 \pm 0.01)$ & $0.017 \%$ \\
60 & 0.616 & 0.01 & 59.994 & $(60 \pm 0.01)$ & $0.017 \%$ \\
60 & 0.940 & 0.01 & 59.991 & $(60 \pm 0.01)$ & $0.017 \%$ \\
60 & 0.355 & 0.01 & 59.996 & $(60 \pm 0.01)$ & $0.017 \%$ \\
65 & 0.411 & 0.01 & 64.996 & $(65 \pm 0.01)$ & $0.015 \%$ \\
65 & 0.984 & 0.01 & 64.990 & $(65 \pm 0.01)$ & $0.015 \%$ \\
65 & 0.946 & 0.01 & 64.991 & $(65 \pm 0.01)$ & $0.015 \%$ \\
65 & 0.677 & 0.01 & 64.993 & $(65 \pm 0.01)$ & $0.015 \%$ \\
45 & 0.988 & 0.01 & 44.990 & $(45 \pm 0.01)$ & $0.022 \%$ \\
45 & 0.767 & 0.01 & 44.992 & $(45 \pm 0.01)$ & $0.022 \%$ \\
45 & 0.337 & 0.01 & 44.997 & $(45 \pm 0.01)$ & $0.022 \%$ \\
45 & 0.662 & 0.01 & 44.993 & $(45 \pm 0.01)$ & $0.022 \%$ \\
45 & 0.244 & 0.01 & 44.998 & $(45 \pm 0.01)$ & $0.022 \%$ \\
45 & 0.296 & 0.01 & 44.997 & $(45 \pm 0.01)$ & $0.022 \%$ \\
45 & 0.680 & 0.01 & 44.993 & $(45 \pm 0.01)$ & $0.022 \%$ \\
45 & 0.528 & 0.01 & 44.995 & $(45 \pm 0.01)$ & $0.022 \%$ \\
\hline
\end{tabular}

\footnotetext{
${ }^{6}$ http://www2.fiu.edu/ dbrookes/ExperimentalUncertaintiesCalculus.pdf Date accessed 10.10.2016
} 
The simulation is run for both measured and true values $A_{m}$ to compare the confidence level of the results of the proposed model. The measured and true value simulation results are presented in Figure 4 and Figure 5 respectively in sub-section 4.3 .

\section{Simulation results and discussion}

The optimal control is modelled for two scenarios. The first scenario simulates a typical day in a dry season when there is low river inflow, modelling a drought season case. The second scenario simulates the performance of the model on a typical day in the rainy season with high in-stream discharge. To validate, the performance advantages of the cascaded pump-back model, simulation for a single pump classical PS model is also carried out for the two scenarios. The comparison of the performance of the two models is presented in sub-section 5 .

\section{Scenario I}

\subsection{Optimal switching operation of the pumpback system}

Figure 2 shows the result of the optimal switching of the cascaded pumpback model and the resultant change in water level of the intermediate reservoir obtained for the case of $w_{1}=w_{2}=w_{3}=w_{4}=0.25$. The minimum operation level of the intermediate reservoir is $10.00 \mathrm{~m}$ while the initial water level is set at $15.00 \mathrm{~m}$. As a result, the OC switches on pump K1 between 00:00 and 12:00 to raise the water level of the intermediate reservoir before bringing in pump $\mathrm{K} 2$ for onward pumping to the main dam. As shown in Figure 2, the OC switches off pump K1 at 12:00 and switches on K2 for the remainder of the control period to keep a high water level in the main dam to optimise the performance of the system. A high water level is necessary to minimise the amount of water discharged per unit of hydropower generated. Also shown in Figure 2 is the power demand of each of the two pumps, which is $4.82 \mathrm{MW}$ whenever in operation, otherwise it is zero. $H_{K 1}(\mathrm{~m})$ and $H_{K 2}(\mathrm{~m})$ are respectively, the change in water level of the intermediate reservoir as a result of the pumping actions of pumps $\mathrm{K} 1$ and $\mathrm{K} 2$ while $\operatorname{Res}_{\text {opt }}(\mathrm{m})$ is the optimal reservoir water level due to the combined pumping actions of the two pumps. As shown, the OC switches on K1 to raise the water level of the intermediate reservoir to $50.0 \mathrm{~m}$ before bringing in $\mathrm{K} 2$ for outward pumping to the main dam. The reservoir water level would fall below its minimum level at 13:00 if pump K2 was operated before K1. The water level decays to the minimum level of $10.0 \mathrm{~m}$ at the end of the day. As shown in Figure 2, the OC alternates the operation of $\mathrm{K} 1$ and $\mathrm{K} 2$ to minimise the pumping power and pumping energy, which is one of the main advantages of the cascaded pumpback model over the classical single pump PS model. 

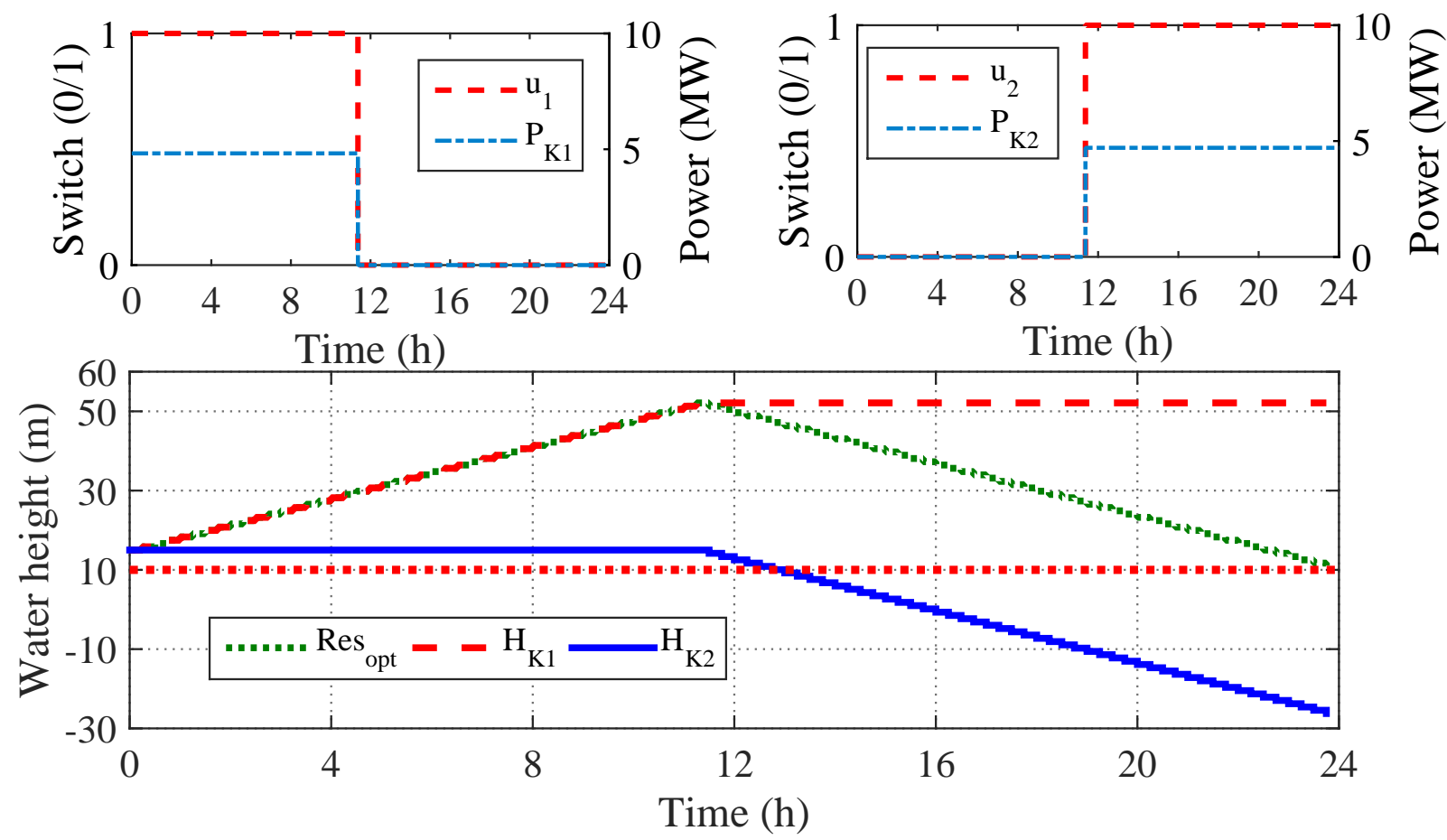

Figure 2: Optimal pump switching and corresponding intermediate reservoir water levels

\subsection{Optimal water level and flow rates of the main dam}

The optimal flow rates and corresponding change in water level of the main dam are shown in Figure 3. In the figure $Q_{o}$ and $Q_{\text {inflow }}$ are respectively, the turbine flow rate for hydropower generation and the combined in-stream discharge and flow rate of pump K2, $Q_{i n}+Q_{2}$. As shown, $Q_{\text {inflow }}$ is $12.5 \mathrm{~m}^{3} / \mathrm{s}$ whenever $\mathrm{K} 2$ is in off mode and $18 \mathrm{~m}^{3} / \mathrm{s}$ whenever $\mathrm{K} 2$ is in operation mode. The turbine flow rate, $Q_{o}$, varies in response to the changes in $P_{g}$ demand. In this case, $Q_{o}$ is $24.45 \mathrm{~m}^{3} / \mathrm{s}$ between 00:00 and 00:15 but decreases to $22.57 \mathrm{~m}^{3} / \mathrm{s}$ between 00:15 and 00:30 in response to a decrease in $P_{g}$ as shown in Figure 4. An increase in $P_{g}$ between 00:30 and 01:00 results in a corresponding increase in $Q_{o}$. Between 01:00 and 04:00, $Q_{o}$ is kept constant at $20.90 \mathrm{~m}^{3} / \mathrm{s}$. However, an increase in $P_{g}$ from 28.37 MW to $38.37 \mathrm{MW}$ at 04:00 results in a corresponding increase in $Q_{o}$ from $20.90 \mathrm{~m}^{3} / \mathrm{s}$ to $28.27 \mathrm{~m}^{3} / \mathrm{s}$. The optimal water level in the dam, $H_{\text {opt }}$ (m) is as a result of the change due to the combined inflows $H_{\text {inflow }}$ less the change due to turbine discharge $H_{Q o}$ (m). The baseline case is depicted by $H_{Q o}(m)$ which is the would be change in the water level of the dam in the absence of the proposed pumpback system. As shown in Figure $3, H_{\text {opt }}$ drops from the initial level of $176.00 \mathrm{~m}$ to $117.10 \mathrm{~m}$ at the end of the day. For the baseline case, the water level in the dam model, $H_{Q o}$, would drop from $176.00 \mathrm{~m}$ to $101.90 \mathrm{~m}$. However, the pumpback system maintains a high water level in the dam to optimise the performance of the plant throughout the control horizon. $H_{\text {inflow }}$ shows the would be water level in the dam model if there was inflows without discharge $Q_{o}$. In this case, the water level of the dam model would rise from $176.00 \mathrm{~m}$ to $257.30 \mathrm{~m}$, leading to an overflow at the end of the day since the maximum operation level of the dam model is $177.50 \mathrm{~m}$. 

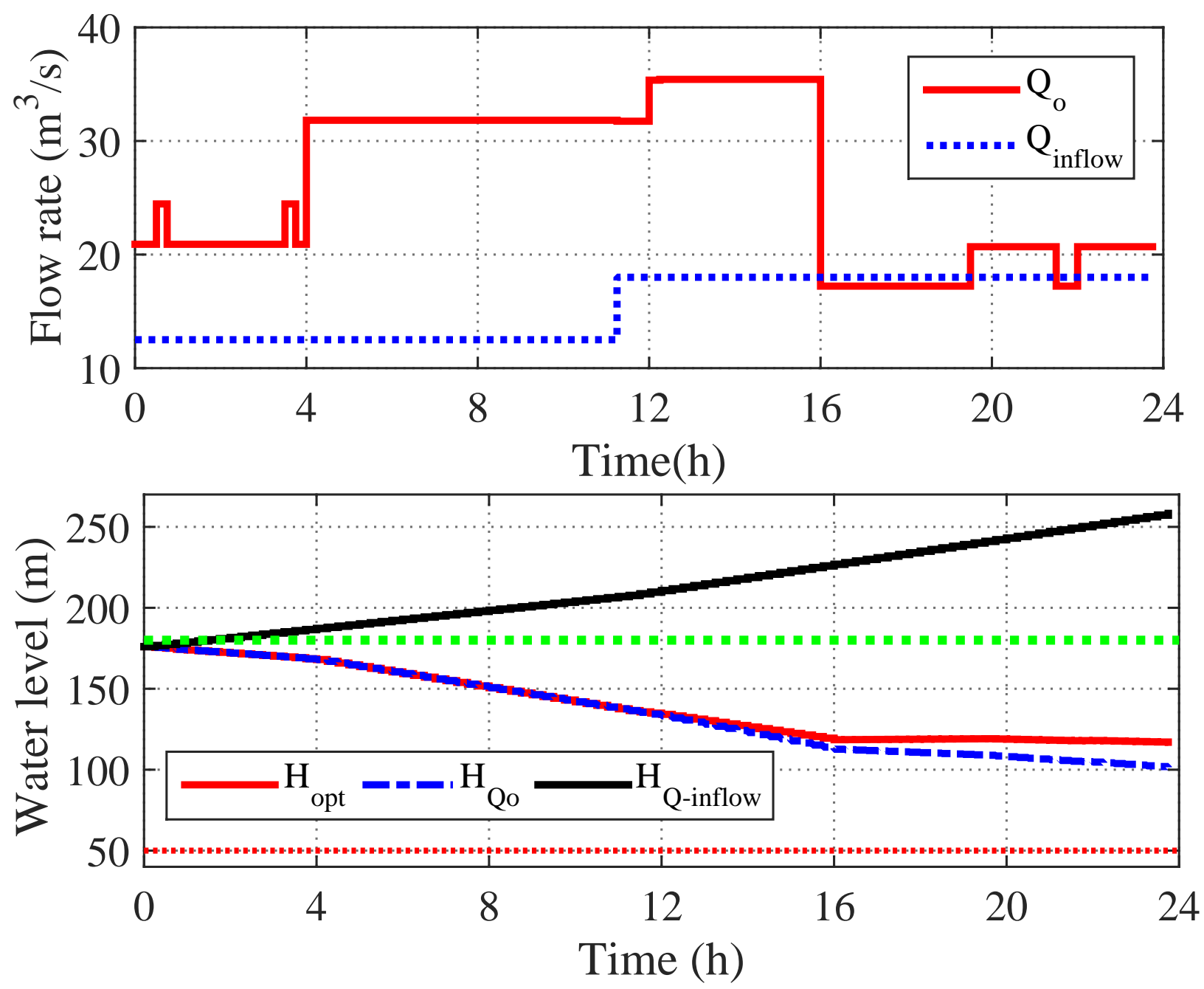

Figure 3: Flow rates and changes in water level of the main dam in dry season

\subsection{Optimal power flows of the system}

Figure 4 and Figure 5 are respectively, the optimal power flows of the system based on measured and true values for the case of $w_{1}=w_{2}=w_{3}=w_{4}=0.25$. Visual inspection of the two figures shows a close match of the power flows simulated from the measured and actual values. However, there are some observable differences in pumping power demand between the two cases. For instance, in Figure 4, the OC uses $P_{h k}$ to meet the pumping power demand between 04:00 and 16:00. Afterwards, $P_{h k}$ is zero between 16:00 and 19:30 and between 21:00 and 22:00 as the OC opts to meet pumping power demand using $P_{g k}$. When true values are used as shown in Figure 5, the OC opts to meet the pumping power demand using $P_{g k}$ between 01:00 and 08:15 before reverting to $P_{h k}$ between 08:15 and 24:00. The net effect between the two cases is a slight difference in daily grid pumping energy demand, $E_{g k}$ : The case of measured values results in $35.74 \mathrm{MWh}$ grid pumping energy demand while the case based on true values results in $35.60 \mathrm{MWh}$ of $E_{g k}$.

As shown in Figure 4, all the on-site generated HK power of $21.62 \mathrm{MW}$ is exported to the grid between 00:00 and 00:15, between 00:45 and 03:30, between 16:00 and 19:30 and between 21:30 and 22:00 as the OC opts to meet the pumping power demand by grid import power, $P_{g k}$. On the other hand, $P_{g}$ varies in response to changes in grid load supplemented by $P_{h g}$. For instance, $P_{g}$ supplies $28.38 \mathrm{MW}$ supplemented by $P_{h g}$ of 21.62 MW to meet the committed demand of 50.00 MW between 00:00 and 00:15. However, a decrease in $P_{h g}$ from 21.62 MW to $16.80 \mathrm{MW}$ at 00:15 against a constant $P_{l d}$ of $50.00 \mathrm{MW}$ results in a corresponding increase in $P_{g}$ from $28.38 \mathrm{MW}$ to $33.20 \mathrm{MW}$. This inverse complementary relationship 
between $P_{g}$ and $P_{h g}$ and, especially between 16:00 and 24:00 is one of the advantages of the proposed optimal control model. A decrease in $P_{g}$ in response to an increase in $P_{h g}$ conserves water in the dam and optimises the energy output of the dam.

Table 6 shows the optimal energy flows of the proposed model simulated for a typical day in dry season using measured values. As shown in the table, weighting factors have effects on the optimal results of the model. In the table, $\mathrm{E}_{\mathrm{K}}(\mathrm{MWh})$ denotes the pumping energy demand of the model which is the summation of HK pumping energy $\mathrm{E}_{\mathrm{hk}}(\mathrm{MWh})$ and grid pumping energy $\mathrm{E}_{\mathrm{gk}}(\mathrm{MWh})$ over the $24 \mathrm{~h}$ control horizon. The optimal energy output, $\mathrm{E}_{\text {opt }}(\mathrm{MWh})$ is the result of summation of hydro-turbine energy output $E_{g}$, excess $\mathrm{HK}$ energy supplied to the grid load, $E_{h g}$ less the grid pumping energy demand, $E_{g k}$. From table 6, the objective function simulated using measured values for the case when $w_{1}=w_{2}=w_{3}=w_{4}=0.25$ results in an optimal hydro-turbine energy output $E_{g}=\sum P_{g} t_{s}=859.5723 \mathrm{MWh}$, where $P_{g}=g \rho H o \eta_{m} \eta_{e} 10^{-6} Q_{o}$. On the other hand, the objective function based on true values gives the total energy $E_{g}=\sum P_{g} t_{s}=859.5684 \mathrm{MWh}$ per day against the energy output simulated from the measured values of $859.5723 \mathrm{MWh}$, which are in close agreement. This proves a low risk of uncertainty implying that the model's results have high confidence level to the margin of:

$$
\triangle E=\sum P_{g} t_{s} \times 0.022 \times 10^{-2}=0.1891,
$$

where $0.022 \times 10^{-2}$ is the weakest link. A value of $\Delta E=0.1891$ gives this model the energy output results with the marginal uncertainty error of $E=(859.5723 \pm 0.1891)$.

As shown in table 6, allocating equal weights to each of the four objective vectors results in $E_{g} k$ demand of 36.60 MWh and $E_{\text {opt }}$ of $1264.30 \mathrm{MWh}$ per day, which translates to $47.09 \%$ increase in the daily energy yield of the resultant system. On the other hand, allocating full priority to minimisation of $E_{g k}$ by setting $w_{1}=1, w_{2}=w_{3}=w_{4}=0$ results in the best optimal solution with lowest grid pumping energy demand, $E_{g k}$ of $34.94 \mathrm{MWh}$ with $47.16 \%$ increase in the overall energy yield of the resultant system. Setting $w_{1}=w_{2}=w_{4}=0, w_{3}=1$, which maximises the restoration of the water level in the main dam by pump K2 results in the highest grid pumping energy demand of $221.53 \mathrm{MWh}$ with $38.09 \%$ increase in the overall energy output of the system. This is expected because maximisation of restoration of the volume of the dam results in continuous pumping operation by $\mathrm{K} 2$ throughout the $24 \mathrm{~h}$ control horizon. As shown in table6, the case of $w_{1}=w_{2}=w_{3}=0, w_{4}=1$ results in the optimal solution with the highest $E_{K}$ of 221.74 MWh with $31.52 \%$ gain in the energy yield of the resultant system, which is the lowest value. The results shown in table 6 provides a framework of reference for decision makers when faced with multiple objectives so that effective trade-offs and choices are made with regard to the priority of each of the sub-objectives. 

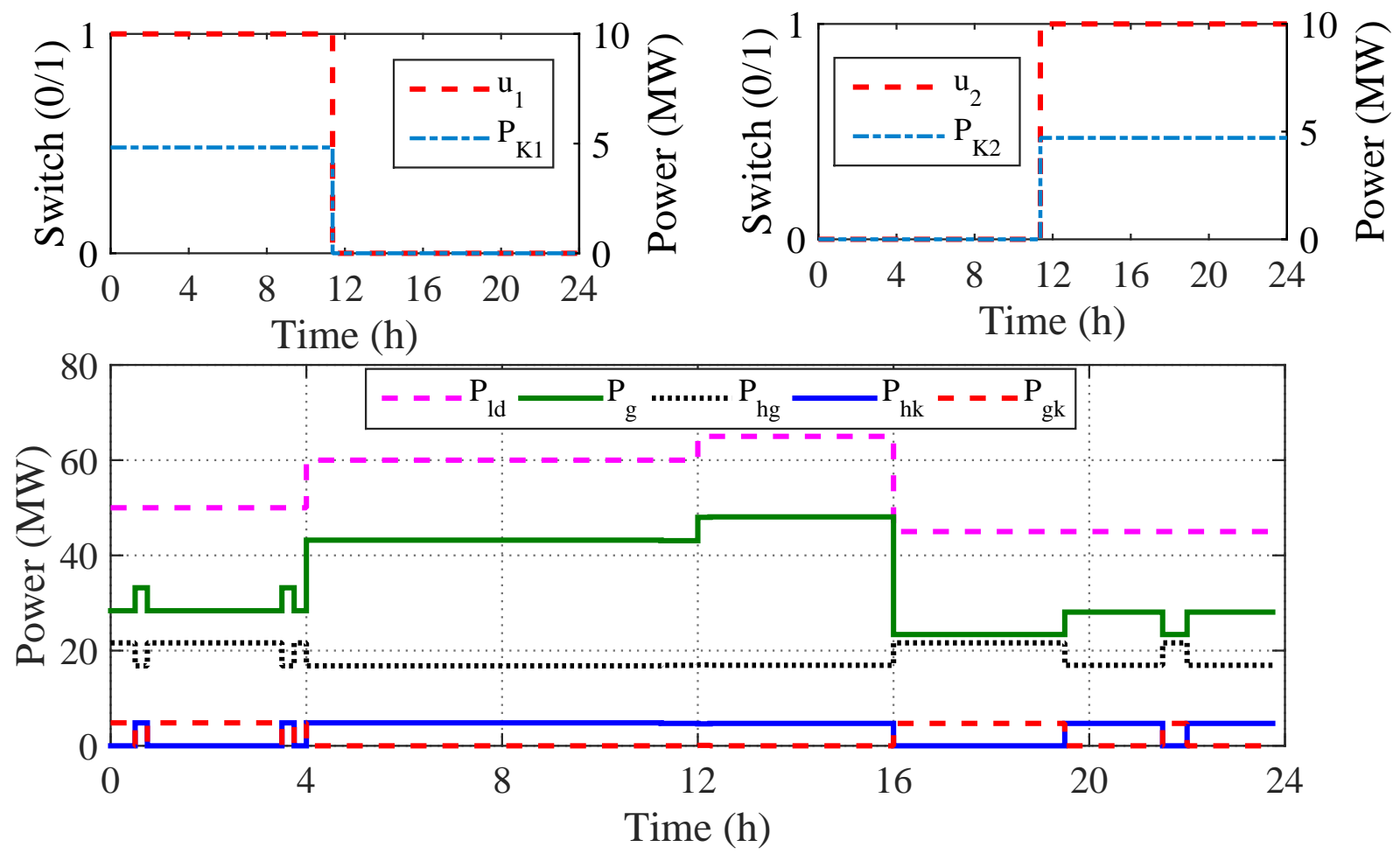

Figure 4: Optimal power flows of the system in dry season
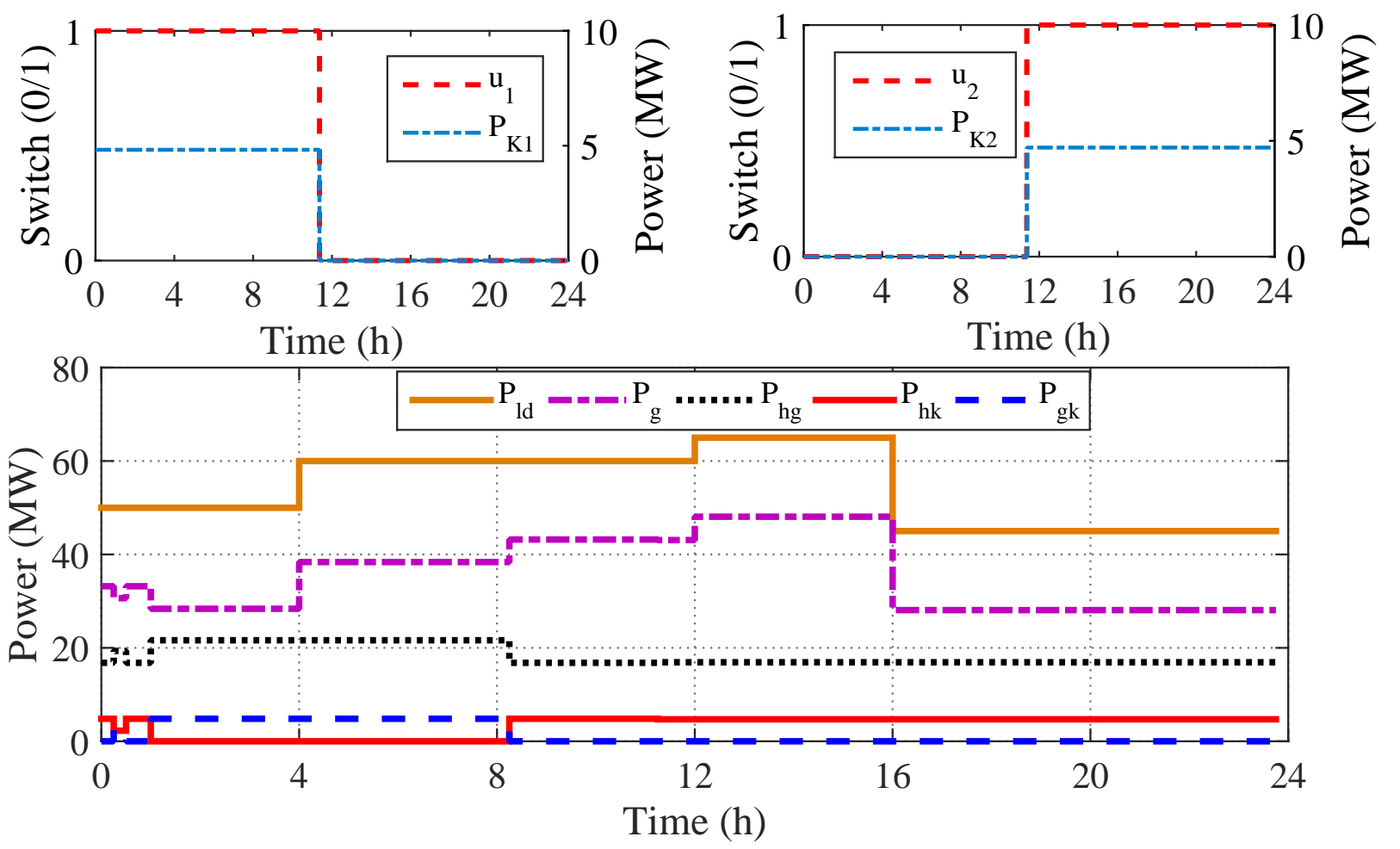

Figure 5: Sensitivity on the optimal power flows of the cascaded model in dry season 
Table 6: Daily optimal energy flows for a cascaded model in dry season

\begin{tabular}{lccccccc}
\hline$\sum_{i=1}^{4} w_{i}=1$ & $E_{g}(\mathrm{MWh})$ & $E_{h g}(\mathrm{MWh})$ & $E_{h k}(\mathrm{MWh})$ & $E_{g k}(\mathrm{MWh})$ & $E_{K}(\mathrm{MWh})$ & $E_{\text {opt }}(\mathrm{MWh})$ & Increase $(\%)$ \\
\hline$w_{1}=w_{2}=w_{3}=w_{4}=0.25$ & 859.57 & 440.29 & 78.69 & 35.60 & 114.30 & 1264.30 & 47.09 \\
$w_{2}=w_{3}=w_{4}=0 ; w_{1}=1$ & 859.57 & 440.29 & 79.36 & 34.94 & 114.30 & 1264.92 & 47.16 \\
$w_{1}=w_{3}=w_{4}=0 ; w_{2}=1$ & 816.16 & 518.99 & 0.00 & 114.98 & 114.98 & 1184.90 & 45.18 \\
$w_{1}=w_{2}=w_{4}=0 ; w_{3}=1$ & 780.18 & 518.99 & 0.00 & 221.53 & 221.53 & 1078.30 & 38.09 \\
$w_{1}=w_{2}=w_{3}=0 ; w_{4}=1$ & 943.00 & 356.30 & 162.68 & 59.06 & 221.74 & 1240.24 & 31.52 \\
\hline
\end{tabular}

\section{Comparison with the classical single pump pumpback model}

The pumpback system for the classical pumped storage (PS) model comprise of a single high lift pump for recycling a part of the down-stream discharge back to the main dam. Figure 6 shows optimal switching, flow rates and power flows of the classical PS model when $w_{1}=w_{2}=w_{3}=w_{4}=0.25$. As shown, for the same initial conditions of the dam and grid power demand, the OC switches pump $K$ throughout the control horizon to maintain the same level of system performance achieved by the cascaded pumpback model. The pumping power demand is $9.19 \mathrm{MW}$ throughout the control period, which is met by $P_{g k}$ between 00:00 and 05:30 and between 19:45 and 20:30, otherwise it is met by $P_{h k}$. Table 7 shows energy flows of the classical single pump pumpback model for the same weighting factors used to simulate the results of the cascaded model shown in table 6. As shown, for the same weighting factors, the pumping energy demand over the control horizon for the classical PS model is far higher as compared to the cascaded pumping model. For instance, for the case when $w_{1}=w_{2}=w_{3}=w_{4}=0.25$, the classical PS model demands $E_{K}$ of 220.59 MWh as compared to $114.30 \mathrm{MWh}$ demanded by the cascaded pumpback model. In this regard, the cascaded pumpback model saves upto $48.18 \%$ of pumping energy when compared to classical single pump PS model. In similar veins, allocation of full optimisation priority to the restoration of the dam water level by setting $w_{1}=w_{2}=w_{4}=0 ; w_{3}=1$, results in an optimal solution with pumping energy demand of 220.59 MWh for the classical PS system, which is in close agreement with the results of the cascaded model for the same weighting factors. This is because the OC switches on all the pumps throughout the control period in both models. In comparison, the use of a cascaded pumping model for this case results in $38.09 \%$ increased in energy yield of the cascaded model as compared to $24.43 \%$ gain achieved by the classical PS model. As shown in table 6 and table 7, allocating full optimisation priority to the maximisation of use of $P_{h k}$ for pumping operation results in optimal solutions with the highest pumping energy demand, $E_{h k}$. For the cascaded model, this operation strategy results in $E_{K}$ of $221.74 \mathrm{MWh}$ while the classical PS model results in $E_{K}$ of $220.59 \mathrm{MWh}$ as shown in table 7.

The high pumping energy for the classical single pump PS model when compared to the cascaded pumpback model is due to the high pumping head bridged by a single pump for the classical PS model. Optimal operation of the cascaded pumpback model reduces the pumping power and pumping energy demand by alternating the operating schedule of the two pumps at some point over the control horizon as shown in Figure 2 resulting in lower daily pumping energy. 

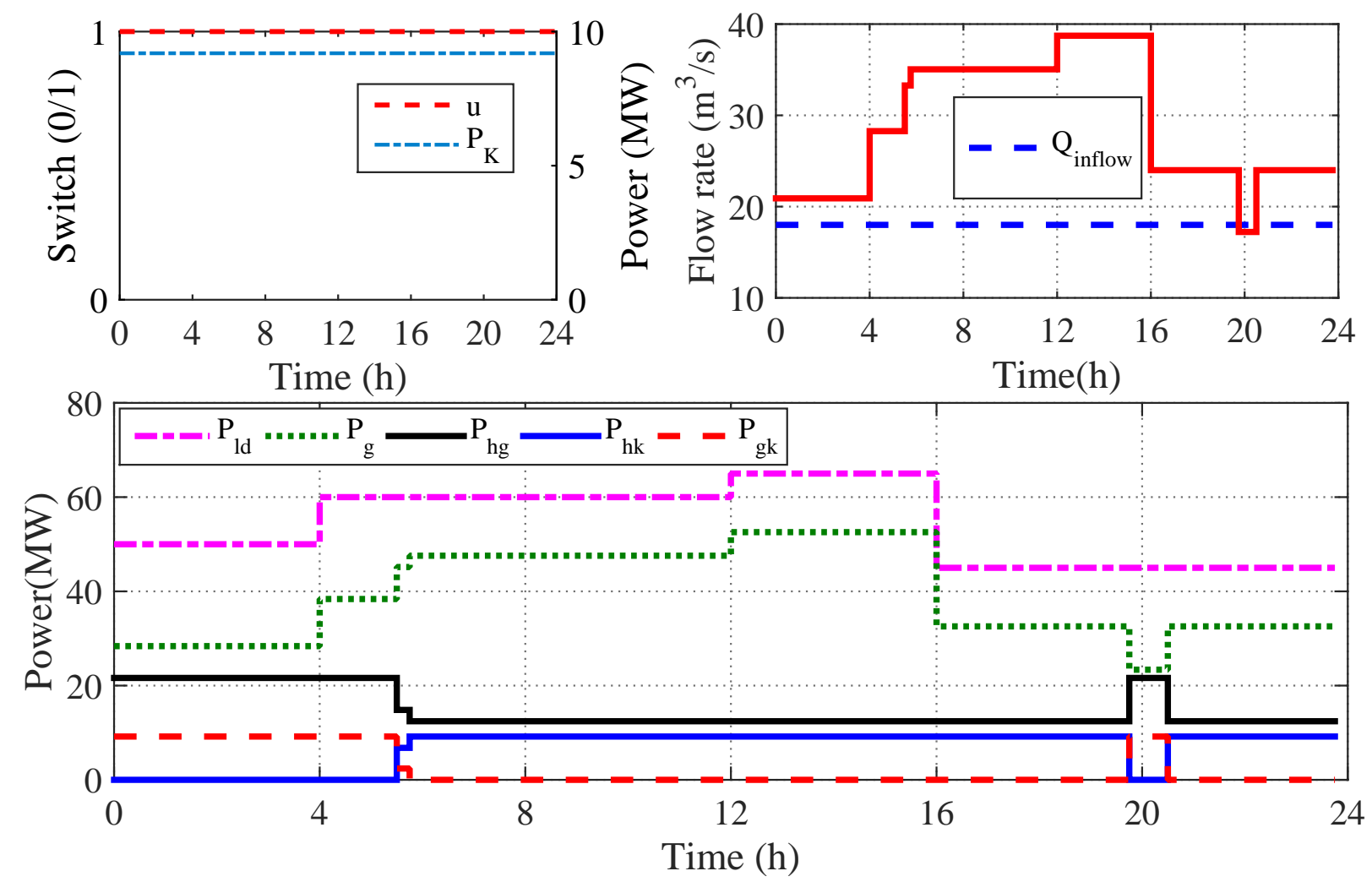

Figure 6: System power balance of the classical PS model in dry season

Table 7: Daily optimal energy flows for a classical PS in dry season

\begin{tabular}{lccccccc}
\hline$\sum_{i=1}^{4} w_{i}=1$ & $E_{g}(\mathrm{MWh})$ & $E_{h g}(\mathrm{MWh})$ & $E_{h k}(\mathrm{MWh})$ & $E_{g k}(\mathrm{MWh})$ & $E_{K}(\mathrm{MWh})$ & $E_{\text {opt }}(\mathrm{MWh})$ & Increase $(\%)$ \\
\hline$w_{1}=w_{2}=w_{3}=w_{4}=0.25$ & 943.56 & 356.44 & 162.54 & 58.05 & 220.59 & 1242.00 & 31.63 \\
$w_{2}=w_{3}=w_{4}=0 ; w_{1}=1$ & 908.63 & 299.05 & 219.94 & 0.00 & 219.94 & 1207.68 & 32.91 \\
$w_{1}=w_{3}=w_{4}=0 ; w_{2}=1$ & 873.92 & 325.79 & 173.20 & 47.28 & 220.48 & 1152.43 & 31.87 \\
$w_{1}=w_{2}=w_{4}=0, w_{3}=1$ & 867.51 & 432.49 & 0.00 & 220.59 & 220.59 & 1079.40 & 24.43 \\
$w_{1}=w_{2}=w_{3}=0 ; w_{4}=1$ & 943.56 & 356.44 & 162.54 & 58.05 & 220.59 & 1242.00 & 31.63 \\
\hline
\end{tabular}

\section{Scenario II}

This is a case of a typical day in the rainy season with high river discharge. Under this scenario, the OC should avoid pumping back water since the river inflows are sufficient to optimally meet the grid power demand.

\subsection{Optimal flow rates of the main dam in rainy season}

During the rainy season, Pangani river discharge increase to an average of $25 \mathrm{~m}^{3} / \mathrm{s}$, which is high enough to cover the committed load demand of the power plant. Figure 7 shows the optimal power flows for the cascaded pumpback model on a typical day in the rainy season. As shown, the OC keeps all the pumps K1 and $\mathrm{K} 2$ in off mode and as a result, all the $518.99 \mathrm{MWh}$ on-site generated HK energy is exported to the grid. Figure 8 shows the optimal flow rates and the corresponding change in the water level of the dam throughout the control horizon. The constant supply of $21.62 \mathrm{MW}$ of HK power results in low demand for $P_{g}$ between 16:00 and 24:00 and as a results, a sharp decrease in $Q_{o}$ from $31.95 \mathrm{~m}^{3} / \mathrm{s}$ to $17.22 \mathrm{~m}^{3} / \mathrm{s}$ is observed. Because of the high in-stream flow of $25.0 \mathrm{~m}^{3} / \mathrm{s}$ as compared to $Q_{o}$ of $17.22 \mathrm{~m}^{3} / \mathrm{s}$, the water level of the dam model rises from $171.90 \mathrm{~m}$, to $184.70 \mathrm{~m}$ between 16:00 and 24:00 as shown in Figure 8 resulting in an increase in the water level of the dam. 

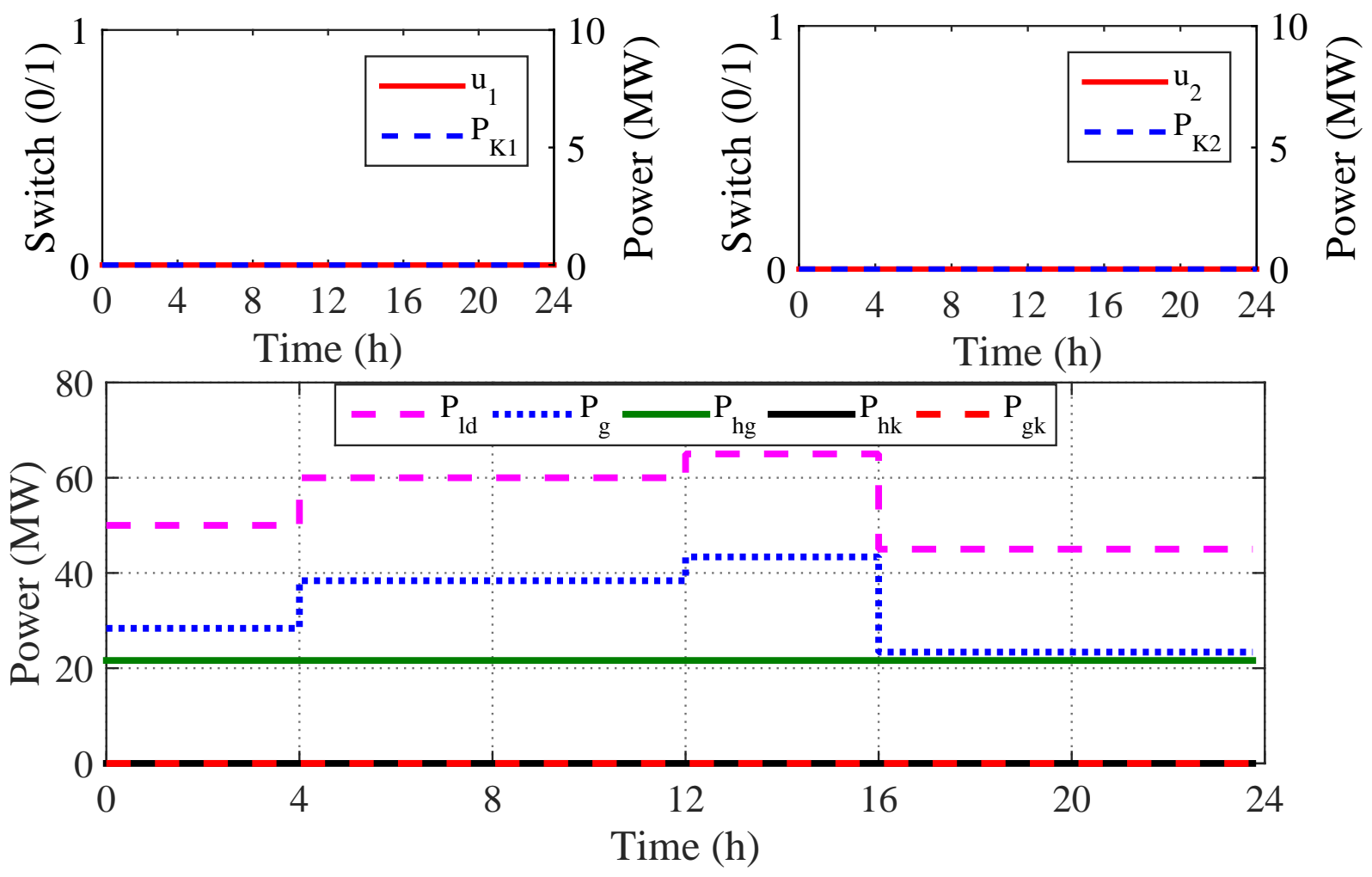

Figure 7: Optimal power balance of the system in rainy season 

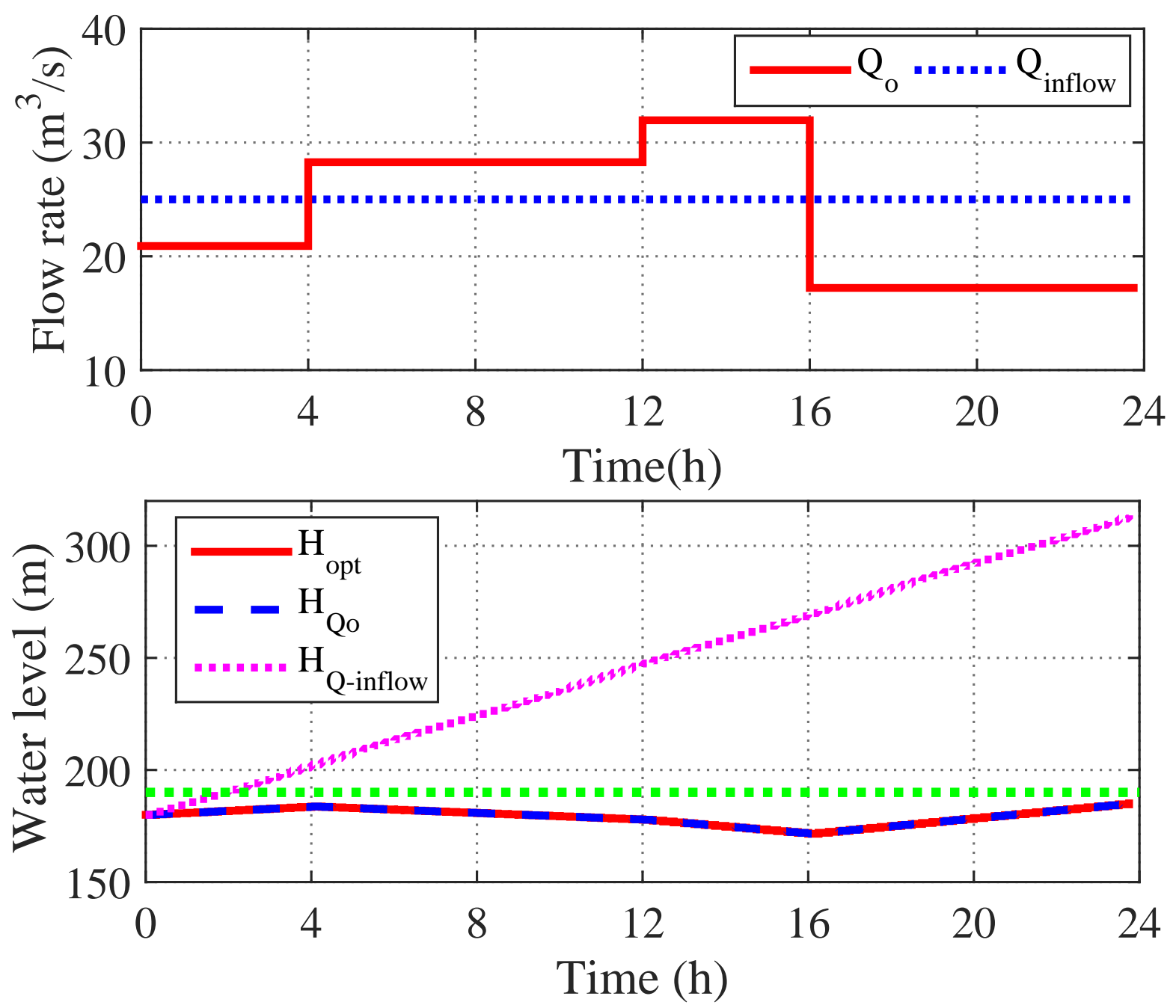

Figure 8: Optimal flow rates and change in water level of the dam in rainy season

Table ?? shows the optimal energy flows of the proposed model for a typical day in the rainy season for the case of $w_{1}=w_{2}=w_{3}=w_{4}=0.25$ for both the cascaded and single pump classical model. $E_{K}$ is zero because the OC opts to operate the pumping system only during a dry season when there is low in-stream flows and low water levels in the dam. All the on-site generated HK energy of $518.99 \mathrm{MWh}$ is exported to the grid resulting in $66.45 \%$ increase in the overall energy yield of the model.

Table 8: Daily optimal energy flows in the rainy season

\begin{tabular}{lccccccc}
\hline$\sum_{i=1}^{4} w_{i}=1$ & $E_{g}(\mathrm{MWh})$ & $E_{h g}(\mathrm{MWh})$ & $E_{h k}(\mathrm{MWh})$ & $E_{g k}(\mathrm{MWh})$ & $E_{K}(\mathrm{MWh})$ & $E_{\text {opt }}(\mathrm{MWh})$ & Increase $(\%)$ \\
\hline$w_{1}=w_{2}=w_{3}=w_{4}=0.25$ & 781.02 & 518.99 & 0.00 & 0.00 & 0.00 & 1300.00 & 66.45 \\
\hline
\end{tabular}

\section{Conclusions}

Pumpback operation to maintain a high water level in the dam can increase the energy output of a HPP in the dry season with low in-stream flows. However, the high pumping energy demand associated with high head high flow pumping can derail the economic viability of the pumping operation. A cascaded pumping model has the potential to reduce the pumping head and through operation scheduling, reduce the pumping power and pumping energy of the pumpback system. An optimal control for a hydropower plant retrofitted with a hydrokinetic powered pumpback system has been presented in the paper. The objective is to maximise 
the energy yield of the plant by simultaneously minimising grid pumping energy demand, minimising the wear and tear of the pumps, maximising the use of the on-site generated hydrokinetic energy for pumping operation and maximising the restoration of the volume of the dam through pumpback operation. Simulation results based on a practical case study shows the potential of the proposed cascaded model to reduce the pumping energy demand upto $48.18 \%$ and increase the overall energy yield of the resultant system by 30 to $48 \%$ in dry season and upto $66.45 \%$ in rainy season. The high increase in energy yield of the plant in the later case is due to the exportation of all the on-site generated hydrokinetic energy to the grid in the absence of the pumping operation. When compared to the single pump classical pumpback model, the cascaded pumpback system shows superior performance with lower pumping energy demand. For the case of allocating equal optimisation priority to the three objective vectors, a cascaded pumping model consumes 114.30 MWh of pumping energy as compared to 220.59 MWh for the classical single pump model. This translates to a pumping energy saving potential of upto $48.18 \%$. For the cascaded pumpback model, the scheduling is observed to alternate the operation of $\mathrm{K} 1$ and $\mathrm{K} 2$ over the control period in order to reduce the overall maximum power demand of the pumps which is one of the main advantages of the cascaded pumping model.

\section{Acknowledgements}

The authors would like to thank the MasterCard Foundation and the National Hub for Energy Efficiency and Demand Side Management-South Africa for financial and other support towards this research.

\section{Appendix A}

\subsection{Equality matrices}

Equation (17) constitute a sparse matrix $\mathbf{A}_{\mathbf{e q} 1}$, given in equation (38) and vector $\mathbf{b}_{\mathbf{e q} 1}$ shown in equation (39) :

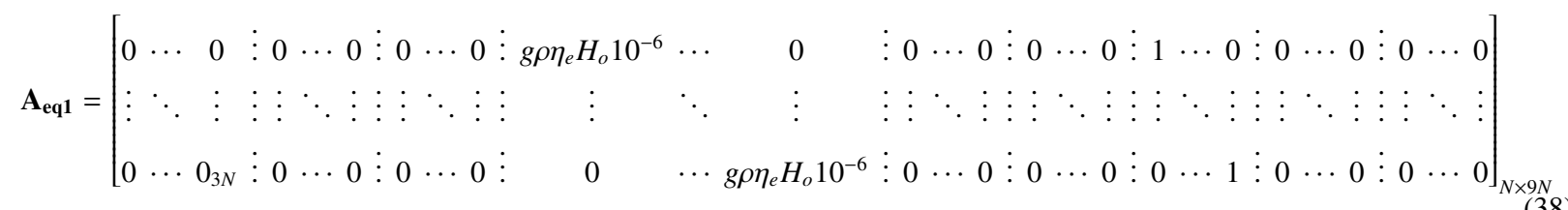

$$
\begin{aligned}
& \mathbf{b}_{\mathbf{e q 1}}=\left[\begin{array}{c}
P_{l d, 1} \\
\vdots \\
P_{l d, N}
\end{array}\right]_{N \times 1} .
\end{aligned}
$$

Similarly, the matrix $\mathbf{A}_{\mathbf{e q} 2}$ shown in equation (40) and vector $\mathbf{b}_{\text {eq3 }}$ shown in equation (41) are constituted from equality constraint (19) for the pump power balance.

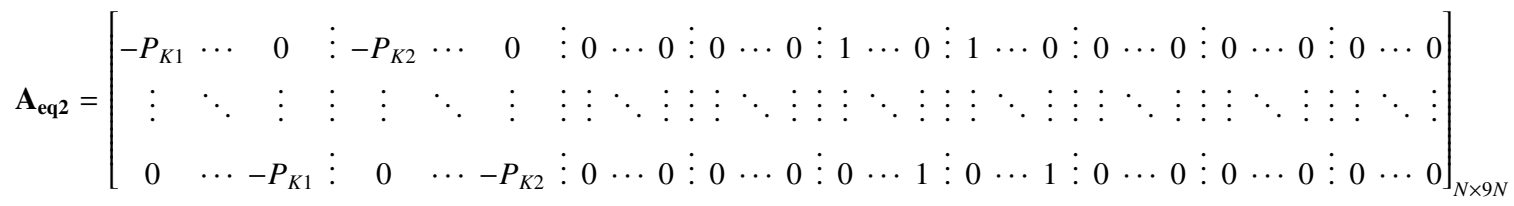

$$
\begin{aligned}
& \mathbf{b}_{\text {eq2 }}=\left[\begin{array}{c}
0_{1} \\
\vdots \\
0_{N}
\end{array}\right]_{N \times 1} .
\end{aligned}
$$

Lastly, the matrix $\mathbf{A}_{\mathbf{e q} 3}$ shown in equation (42) and vector $\mathbf{b}_{\mathbf{e q}} \mathbf{3}$ shown in equation (43) are constituted from the HK power balance of equation (18). 


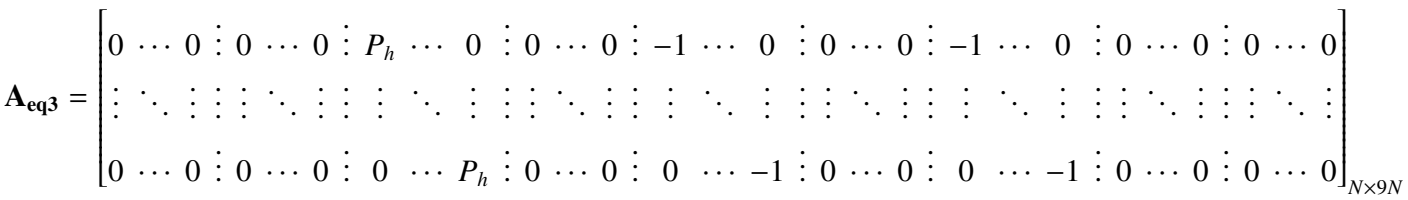

$$
\begin{aligned}
& \mathbf{b}_{\mathbf{e q} 3}=\left[\begin{array}{c}
0_{1} \\
\vdots \\
0_{N}
\end{array}\right]_{N \times 1}
\end{aligned}
$$

The canonical form, $\mathbf{A}_{\mathbf{e q}} \mathbf{X}=\mathbf{b}_{\mathbf{e q}}$ is given in equation (44).

$$
\mathbf{A}_{\text {eq }}=\left[\begin{array}{l}
\mathbf{A}_{\text {eq1 }} \\
\mathbf{A}_{\text {eq2 }} \\
\mathbf{A}_{\text {eq3 } 3}
\end{array}\right]_{3 N \times 7 N}, \quad \mathbf{b}_{\text {eq }}=\left[\begin{array}{l}
\mathbf{b}_{\text {eq1 }} \\
\mathbf{b}_{\text {eq2 } 2} \\
\mathbf{b}_{\text {eq3 } 3}
\end{array}\right]_{3 N \times 1},
$$

\subsection{Inequality matrices}

The general formulation of the inequality constraint is shown in equation (45):

$$
\mathbf{A X} \leqslant \mathbf{b} .
$$

Expression (15) constitute the upper boundary matrix $\mathbf{A}_{\mathbf{1}}$ given by equation (46) and the upper boundary vector $\mathbf{b}_{\mathbf{1}}$ given by equation (47). Where the lower boundary matrix $\mathbf{A}_{\mathbf{2}}=-\mathbf{A}_{\mathbf{1}}$ and the lower boundary vector $\mathbf{b}_{\mathbf{2}}$ is given by equation (48).

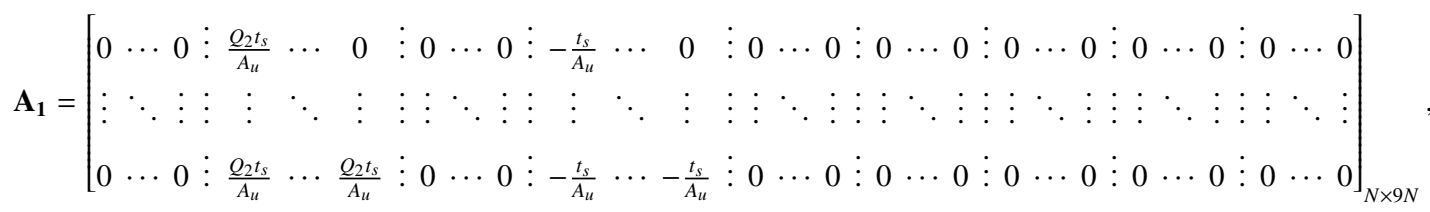

$$
\begin{aligned}
& \mathbf{b}_{1}=\left[\begin{array}{c}
h_{u}^{\max }-h_{u, 0}-\frac{Q_{i n} t_{s}, 1}{A_{u}} \\
\vdots \\
h_{u}^{\max }-h_{u, 0}-\frac{Q_{i n} t_{s}, N}{A_{u}}
\end{array}\right]_{N \times 1}, \\
& \mathbf{b}_{2}=\left[\begin{array}{c}
-h_{u}^{\min }+h_{u, 0}+\frac{Q_{\text {in }} t_{s}, 1}{A_{u}} \\
\vdots \\
-h_{u}^{\min }+h_{u, 0}+\frac{Q_{i n} t_{s}, N}{A_{u}}
\end{array}\right]_{N \times 1} .
\end{aligned}
$$

Similarly, the inequality constraint (16) constitute the matrix $\mathbf{A}_{\mathbf{3}}$ given by equation (49) and vector $\mathbf{b}_{\mathbf{3}}$ expressed by equation (50):

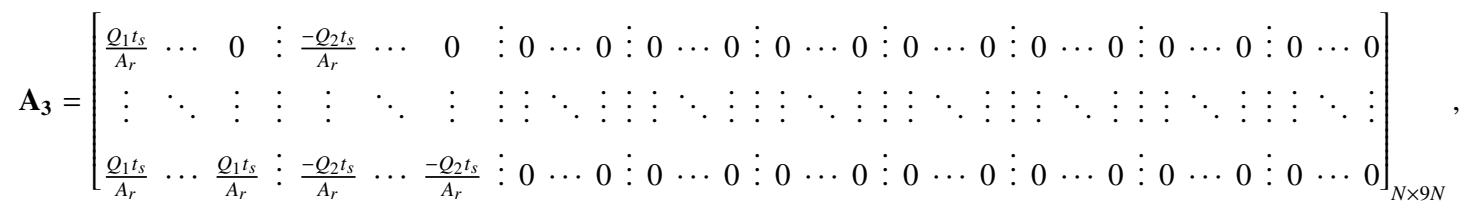

$$
\begin{aligned}
& \mathbf{b}_{3}=\left[\begin{array}{c}
h_{r}^{\max }-h_{r, 0} \\
\vdots \\
h_{r}^{\max }-h_{r, 0}
\end{array}\right]_{N \times 1} .
\end{aligned}
$$


The lower boundary matrix of the intermediate reservoir $\mathbf{A}_{\mathbf{4}}=-\mathbf{A}_{\mathbf{3}}$ and lower limit vector $\mathbf{b}_{\mathbf{4}}$ is given by equation (51).

$$
\mathbf{b}_{4}=\left[\begin{array}{c}
-h_{r}^{\min }+h_{r, 0} \\
\vdots \\
-h_{r}^{\min }+h_{r, 0}
\end{array}\right]_{N \times 1} \text {. }
$$

By letting

$$
A_{51}=\left[\begin{array}{ccccc}
1 & 0 & 0 & \ldots & 0 \\
-1 & 1 & 0 & \ldots & 0 \\
0 & -1 & 1 & \ldots & 0 \\
\vdots & \vdots & \ddots & \ddots & \vdots \\
0 & 0 & \ldots & -1 & 1
\end{array}\right], \quad A_{52}=\left[\begin{array}{ccccc}
-1 & 0 & 0 & \ldots & 0 \\
0 & -1 & 0 & \ldots & 0 \\
0 & 0 & -1 & \ldots & 0 \\
\vdots & \vdots & \vdots & \ddots & \vdots \\
0 & 0 & 0 & \ldots & -1
\end{array}\right]
$$

then, inequality (25) can be written as

$$
\begin{aligned}
A_{5} & =\left[\begin{array}{lllll}
A_{51} & A_{51} & (0 \ldots 0)_{5 N} & A_{52} & A_{52}
\end{array}\right] \\
b_{5} & =\left[\begin{array}{lllll}
0 & 0 & 0 & \ldots & 0
\end{array}\right]^{T}
\end{aligned}
$$

Thus, the final expression of the matrix $\mathbf{A}$ and vector $\mathbf{b}$ is given by equation (54)

$$
\mathbf{A}=\left[\begin{array}{l}
\mathbf{A}_{\mathbf{1}} \\
\mathbf{A}_{\mathbf{2}} \\
\mathbf{A}_{\mathbf{3}} \\
\mathbf{A}_{\mathbf{4}} \\
\mathbf{A}_{\mathbf{5}}
\end{array}\right]_{5 N \times 9 N}, \quad \mathbf{b}=\left[\begin{array}{l}
\mathbf{b}_{\mathbf{1}} \\
\mathbf{b}_{2} \\
\mathbf{b}_{3} \\
\mathbf{b}_{\mathbf{4}} \\
\mathbf{b}_{\mathbf{5}}
\end{array}\right]_{5 N \times 1}
$$

\section{References}

[1] M. T. van Vliet, D. Wiberg, S. Leduc, K. Riahi, Power-generation system vulnerability and adaptation to changes in climate and water resources, Nature Climate Change 6 (2016) 375-380.

[2] R. Beilfuss, A risky climate for southern african hydro, International Rivers, Berkely.

[3] G. P. Harrison, H. Whittington, Vulnerability of hydropower projects to climate change, in: IEE Proceedings - Generation, Transmission and Distribution, Vol. 149, IET, 2002, pp. 249-255.

[4] W. W.-G. Yeh, Reservoir management and operations models: A state-of-the-art review, Water resources research 21 (12) (1985) 1797-1818.

[5] J. W. Labadie, Optimal operation of multireservoir systems: state-of-the-art review, Journal of water resources planning and management 130 (2) (2004) 93-111.

[6] P. M. Jacovkis, H. Gradowczyk, A. M. Freisztav, E. G. Tabak, A linear programming approach to water-resources optimization, Zeitschrift für Operations Research 33 (5) (1989) 341-362.

[7] B. K. Edwards, S. J. Flaim, R. E. Howitt, Optimal provision of hydroelectric power under environmental and regulatory constraints, Land Economics (1999) 267-283.

[8] H. Gao, C. Wang, A optimal operation scheduling method of pumped storage station and thermal power station coordination, in: 2006 IEEE PES Power Systems Conference and Exposition, IEEE, 2006, pp. 1829-1832.

[9] R.-H. Liang, A noise annealing neural network for hydroelectric generation scheduling with pumped-storage units, IEEE Transactions on Power Systems 15 (3) (2000) 1008-1013.

[10] G. Pritchard, A. B. Philpott, P. J. Neame, Hydroelectric reservoir optimization in a pool market, Mathematical programming 103 (3) (2005) 445-461.

[11] J.-H. Yoo, Maximization of hydropower generation through the application of a linear programming model, Journal of Hydrology 376 (1) (2009) 182-187.

[12] R. Loisel, A. Mercier, C. Gatzen, N. Elms, H. Petric, Valuation framework for large scale electricity storage in a case with wind curtailment, Energy Policy 38 (11) (2010) 7323-7337.

[13] N. Lu, J. H. Chow, A. A. Desrochers, Pumped-storage hydro-turbine bidding strategies in a competitive electricity market, IEEE Transactions on Power Systems 19 (2) (2004) 834-841.

[14] A. I. Cohen, S. Wan, An algorithm for scheduling a large pumped storage plant, IEEE Transactions on Power Apparatus and Systems (8) (1985) 2099-2104. 
[15] X. Guan, P. B. Luh, H. Yen, P. Rogan, Optimization-based scheduling of hydrothermal power systems with pumped-storage units, IEEE Transactions on Power Systems 9 (2) (1994) 1023-1031.

[16] W. Li, J. Huang, G. Li, Z. Wang, Research on optimizing operation of the single reservoir of hybrid pumped storage power station, in: 2011 4th International Conference on Electric Utility Deregulation and Restructuring and Power Technologies (DRPT), IEEE, 2011, pp. 1389-1394.

[17] G. Zhao, M. Davison, Optimal control of hydroelectric facility incorporating pump storage, Renewable Energy 34 (4) (2009) 1064-1077.

[18] K. E. Lansey, K. Awumah, Optimal pump operations considering pump switches, Journal of Water Resources Planning and Management 120 (1) (1994) 17-35.

[19] X. Zhuan, X. Xia, Optimal operation scheduling of a pumping station with multiple pumps, Applied Energy 104 (2013) $250-257$.

[20] Y. Tang, G. Zheng, S. Zhang, Optimal control approaches of pumping stations to achieve energy efficiency and load shifting, International Journal of Electrical Power \& Energy Systems 55 (2014) 572-580.

[21] E. M. Wanjiru, L. Zhang, X. Xia, Model predictive control strategy of energy-water management in urban households, Applied Energy 179 (2016) 821-831.

[22] A. Arce, T. Ohishi, S. Soares, Optimal dispatch of generating units of the itaipú hydroelectric plant, , IEEE Transactions on Power Systems 17 (1) (2002) 154-158.

[23] Y. Tang, G. Zheng, S. Zhang, Optimal control approaches of pumping stations to achieve energy efficiency and load shifting, International Journal of Electrical Power and Energy Systems 55 (2014) 572 - 580.

[24] L. Lago, F. Ponta, L. Chen, Advances and trends in hydrokinetic turbine systems, Energy for Sustainable Development 14 (4) (2010) 287-296.

[25] S. Ashok, Optimised model for community-based hybrid energy system, Renewable energy 32 (7) (2007) $1155-1164$.

[26] S. Sichilalu, T. Mathaba, X. Xia, Optimal control of a wind-pv-hybrid powered heat pump water heater, Applied Energy (2015) , In press, Corrected proof. doi:http://dx.doi.org/10.1016/j .apenergy .2015.10.072.

[27] E. M. Wanjiru, X. Xia, Energy-water optimization model incorporating rooftop water harvesting for lawn irrigation, Applied Energy 160 (2015) 521-531.

[28] R. Kimwaga, S. Nkandi, Evaluation of the suitability of pangani falls redevelopment (hydro power) project in pangani river basin, tanzania: An iwrm approach.

[29] K. Luteganya, S. Kizzy, Hydroelectric power modelling study. pangani river basib flow assessment, Print (January 2009).

[30] S. M. Sichilalu, X. Xia, Optimal energy control of grid tied pv-diesel-battery hybrid system powering heat pump water heater, Solar Energy 115 (2015) 243-254. 